\title{
Dopamine Receptor Activation Is Required for Corticostriatal Spike-Timing-Dependent Plasticity
}

\author{
Verena Pawlak ${ }^{1,2}$ and Jason N. D. Kerr ${ }^{2}$ \\ ${ }^{1}$ Department of Cell Physiology, Max Planck Institute for Medical Research, 69120 Heidelberg, Germany, and ²Network Imaging Group, Max Planck \\ Institute for Biological Cybernetics, 72076 Tübingen, Germany
}

\begin{abstract}
Single action potentials (APs) backpropagate into the higher-order dendrites of striatal spiny projection neurons during cortically driven "up" states. The timing of these backpropagating APs relative to the arriving corticostriatal excitatory inputs determines changes in dendritic calcium concentration. The question arises to whether this spike-timing relative to cortical excitatory inputs can also induce synaptic plasticity at corticostriatal synapses. Here we show that timing of single postsynaptic APs relative to the cortically evoked EPSP determines both the direction and the strength of synaptic plasticity in spiny projection neurons. Single APs occurring $30 \mathrm{~ms}$ before the cortically evoked EPSP induced long-term depression (LTD), whereas APs occurring $10 \mathrm{~ms}$ after the EPSP induced long-term potentiation (LTP). The amount of plasticity decreased as the time between the APs and EPSPs was increased, with the resulting spike-timing window being broader for LTD than for LTP. In addition, we show that dopamine receptor activation is required for this spike-timing-dependent plasticity (STDP). Blocking dopamine $\mathrm{D}_{1} / \mathrm{D}_{5}$ receptors prevented both LTD and LTP induction. In contrast, blocking dopamine $\mathrm{D}_{2}$ receptors delayed, but did not prevent, LTD and sped induction of LTP. We conclude (1) that, in combination with cortical inputs, single APs evoked in spiny projection neurons can induce both LTP and LTD of the corticostriatal pathway; (2) that the strength and direction of these synaptic changes depend deterministically on the AP timing relative to the arriving cortical inputs; (3) that, whereas dopamine $\mathrm{D}_{2}$ receptor activation modulates the initial phase of striatal STDP, dopamine $D_{1} / D_{5}$ receptor activation is critically required for striatal STDP. Thus, the timing of APs relative to cortical inputs alone is not enough to induce corticostriatal plasticity, implying that ongoing activity does not affect synaptic strength unless dopamine receptors are activated.
\end{abstract}

Key words: striatum; basal ganglia; NMDA receptors; spiny projection neuron; synaptic plasticity; excitatory synaptic transmission

\section{Introduction}

The interaction of dopamine and glutamate at dendritic spines located on striatal spiny projection neurons (SPNs) is central to many models of corticostriatal synaptic plasticity (Wickens, 1990; Wickens et al., 1991; Wickens and Arbuthnott, 1993; Kotter and Wickens, 1995; Arbuthnott et al., 1998; Schultz, 2002). Exactly how activity arriving from the cortex exerts changes on its synaptic targets in the neostriatum is still a matter of debate and is not well understood (Calabresi et al., 1992b, 1994; Wickens and Arbuthnott, 1993; Choi and Lovinger, 1997a; Reynolds and Wickens, 2000; Kerr and Wickens, 2001; Fino et al., 2005; Wang et al., 2006). It is nevertheless clear that dopamine receptor activation plays a central role in corticostriatal plasticity, whether structural plasticity (Ingham et al., 1989; Day et al., 2006; Gerfen, 2006) or synaptic plasticity induced using high-frequency affer-

Received Sept. 26, 2007; revised Dec. 14, 2007; accepted Jan. 9, 2008.

This work was supported by the Max Planck Society and by Deutsche Forschungsgemeinschaft Grant PA1503/1-1 (V.P.). We thank Bert Sakmann and Fritjof Helmchen for generous support, Marlies Kaiser for outstanding technical assistance, Damian Wallace and Jeff Wickens for helpful comments on a previous version of this manuscript, and David Greenberg for providing help with data analysis. J.N.D.K. and V.P. designed the experiments and wrote this manuscript. V.P. performed the experiments and did the analyses.

Correspondence should be addressed to either Verena Pawlak or Jason N. D. Kerr, Network Imaging Group, Max Planck Institute for Biological Cybernetics, Spemannstrasse 41, 72076 Tübingen, Germany, E-mail: verena.pawlak@tuebingen.mpg.de or jason@tuebingen.mpg.de.

D0I:10.1523/JNEUROSCI.4402-07.2008

Copyright $\odot 2008$ Society for Neuroscience $\quad$ 0270-6474/08/282435-12\$15.00/0 ent stimulation (HFS) (Calabresi et al., 1992b; Wickens et al., 1996; Reynolds and Wickens, 2000; Kerr and Wickens, 2001; Reynolds et al., 2001). Because action potential (AP) firing, which is generally necessary for synaptic plasticity induction, is sparse in both cortical (Margrie et al., 2002; Brecht et al., 2003; Manns et al., 2004; Kerr et al., 2005; Lee et al., 2006; de Kock et al., 2007) and striatal spiny projection neurons in vivo, with single spikes occurring often (Wilson and Groves, 1981; Calabresi et al., 1990; Wilson and Kawaguchi, 1996; Wickens and Wilson, 1998; Mahon et al., 2006), HFS-based protocols may not translate well to in vivo-like activity. In addition, in many cortical areas including those that project to the striatum, synaptic plasticity has been induced using protocols that rely on the exact timing of postsynaptic APs in relation to presynaptic excitatory inputs (Magee and Johnston, 1997; Markram et al., 1997). Accordingly, this spiketiming-dependent (STDP) plasticity is now accepted as a likely candidate for eliciting changes in synaptic efficacy between neurons in vivo (Celikel et al., 2004; Jacob et al., 2007). For STDP, the order and precise timing of presynaptic and postsynaptic activation determines both the direction and extent of synaptic change (Markram et al., 1997; Bi and Poo, 1998; Feldman, 2000; Jacob et al., 2007) as well as postsynaptic dendritic calcium levels (Magee and Johnston, 1997; Koester and Sakmann, 1998; Nevian and Sakmann, 2004).

In striatal SPNs, increases in dendritic calcium are dictated by the 
precise timing of single backpropagating APs relative to the onset of cortically driven striatal "up" states (Kerr and Plenz, 2004): single AP-induced dendritic calcium transients were highest when APs occurred close to up-state onset. Similarly, SPN spines displayed maximal calcium influx when synaptic inputs were followed by backpropagating APs (Carter and Sabatini, 2004). The question then arises whether the precise timing of single APs in SPNs relative to excitatory corticostriatal inputs induces synaptic plasticity. If so, then the next question is whether dopamine receptor activation is necessary for this form of synaptic plasticity as has been shown for HFS-induced plasticity.

In the present study, we show that spike-timing-dependent plasticity is induced in the corticostriatal pathway and requires dopamine $\mathrm{D}_{1} / \mathrm{D}_{5}$ receptor activation. Long-term potentiation (LTP) was induced when the AP closely followed the cortically evoked EPSP, whereas long-term depression (LTD) was induced when the AP preceded the EPSP. We show that, in addition to the precise timing of APs relative to cortically evoked EPSPs, a third factor, dopamine, is required for changes in corticostriatal synaptic efficacy. This suggests that the timing of AP generation in striatal SPNs is critical for conveying information about striatal output back to the spines involved in generating that output. However, for these events to exert longterm changes in basal ganglia activity, a reinforcement signal from the dopamine pathway must be present.

\section{Materials and Methods}

Slice preparation. All experimental procedures were performed according to the animal welfare guidelines of the Max Planck Society. Wistar rats (19-22 d old) were anesthetized with isoflurane and decapitated. The brain was quickly removed and sectioned in oxygenated, ice-cold modified artificial CSF (mACSF). Para-horizontal corticostriatal slices, 350 $\mu \mathrm{m}$ thick, were prepared in such a way as to keep the corticostriatal projection fibers intact (Arbuthnott et al., 1985; Kerr and Wickens, 2001). The mACSF contained the following (in mM): 240 sucrose, 2.5 $\mathrm{KCl}, 7 \mathrm{MgSO}_{4}, 1.25 \mathrm{NaH}_{2} \mathrm{PO}_{4}, 25 \mathrm{NaHCO}_{3}, 10$ glucose, and $0.5 \mathrm{CaCl}_{2}$. Slices were transferred to a holding chamber and maintained at room temperature $\left(22-23^{\circ} \mathrm{C}\right)$ until use within $1-6 \mathrm{~h}$ after slice preparation. ACSF for slice storage and recording contained the following (in $\mathrm{mM}$ ): $124 \mathrm{NaCl}, 2.5 \mathrm{KCl}, 2.0 \mathrm{MgSO}_{4}, 2.5 \mathrm{CaCl}_{2}, 1.25 \mathrm{NaH}_{2} \mathrm{PO}_{4}, 26 \mathrm{NaHCO}_{3}$, and 11 glucose ( $310 \mathrm{mOsm}, \mathrm{pH} 7.4$, bubbled with $95 \% \mathrm{O}_{2} / 5 \% \mathrm{CO}_{2}$ ).

Electrophysiological recordings. A slice was transferred to the recording chamber and continuously superfused with ACSF at $31-33^{\circ} \mathrm{C}$. Wholecell current-clamp recordings were made with an Axoclamp 2B amplifier (Molecular Devices, Union City, CA). Data was filtered at $2 \mathrm{kHz}$ and digitized at $10-20 \mathrm{kHz}$ with an ITC-16 (InstruTech, Port Washington, NY) using custom data acquisition and analysis routines running in Igor (WaveMetrics, Lake Oswego, OR). Spiny projection neurons in dorsolateral striatum were visualized using infrared differential interference optics video microscopy and identified by their morphology (small somata, post hoc biocytin staining revealed multiple primary dendrites with a high spine density in their oblique branches). In addition, SPNs were identified by their intrinsic membrane properties [e.g., resting membrane potential was typically more negative than $-80 \mathrm{mV}$, inward and outward rectification in response to somatic current injection, a long depolarizing ramp to the AP threshold leading to a delayed spike discharge (delay from onset of current injection to first AP was typically longer than $120 \mathrm{~ms}$ ) (for more details, see supplemental Table 1, available at www.jneurosci.org as supplemental material)]. Recording electrodes (5-9 M $\Omega$ ) were made from borosilicate glass and filled with intracellular solution containing the following: $120 \mathrm{~mm} \mathrm{~K}$-gluconate, $20 \mathrm{~mm} \mathrm{KCl}, 10$ mM HEPES, $4 \mathrm{~mm} \mathrm{NaCl}, 4 \mathrm{~mm}$ ATP-Mg, $0.3 \mathrm{~mm}$ GTP-Na, $10 \mathrm{~mm}$ phosphocreatine-Na, and $0.2 \%$ biocytin, $\mathrm{pH} 7.35$ (310 mOsm). Liquid junction potential was $-13 \mathrm{mV}$ and not corrected for. For all experiments, $50 \mu \mathrm{M}$ picrotoxin $\left(\mathrm{GABA}_{\mathrm{A}}\right.$ receptor blocker) and $10 \mu \mathrm{M}$ glycine [NMDA receptor (NMDAR) coagonist] was added to the ACSF. When indicated, the AMPA receptor (AMPAR) antagonist CNQX (100 $\mu \mathrm{M})$, the NMDA receptor antagonist D-AP-5 $(50 \mu \mathrm{M})$, the dopamine $\mathrm{D}_{1} / \mathrm{D}_{5}$ receptor antagonist $\mathrm{SCH}-23390[R(+)$-7-chloro-8-hydroxy-3-methyl1-phenyl-2,3,4,5-tetrahydro-1 H-3-benzazepine hydrochloride] (10 $\mu \mathrm{M})$, or the dopamine $\mathrm{D}_{2}$ receptor antagonist $(S)-(-)$ sulpiride $(10 \mu \mathrm{M})$ were added to the ACSF.

Corticostriatal pathway stimulation. EPSPs were evoked in SPNs by extracellular stimulation $(0.02 \mathrm{~ms}$, at $0.1-0.067 \mathrm{~Hz})$ with bipolar platinum/iridium electrodes (FHC, Bowdoinham, ME) placed in cortical layer 5 or close to white matter. In addition, we kept stimulation intensities $(11.8 \pm 0.9 \mathrm{~V})$ as low as possible (to prevent current spread) in such a way that an EPSP with one clearly defined peak was observed with no intermittent EPSP failures. SPNs series resistance $\left(R_{\mathrm{s}}\right)$ was $8-30 \mathrm{M} \Omega$, and input resistance $\left(R_{\mathrm{i}}\right)$ was $59-300 \mathrm{M} \Omega$. $R_{\mathrm{i}}$ was estimated from the response to a hyperpolarizing current step ( $-25 \mathrm{pA}$ for $200 \mathrm{~ms})$. Recordings were rejected if the initial $V_{\mathrm{m}}$ was more positive than $-80 \mathrm{mV}$ or if $V_{\mathrm{m}}$ changed by $>8 \%$ and $R_{\mathrm{i}}$ changed by $>30 \%$ during the course of the recording. For baseline recordings, EPSP amplitudes were recorded over a period of $10 \mathrm{~min}$ (baselines were comparable between experiments in control ACSF and under dopamine receptor block) (supplemental Fig. 3, available at www.jneurosci.org as supplemental material). EPSPs were then paired with an AP at the indicated time delay $(\Delta t)$, repeated 60 times. The presynaptic stimulation frequency during these 60 pairings remained low $(0.1 \mathrm{~Hz})$ as in the baseline period, because higher repetition rates can confound both the spike-timing window and the direction of plasticity in other brain regions (Sjostrom et al., 2001; Tzounopoulos et al., 2004; Wittenberg and Wang, 2006). Also in the corticostriatal pathway, already a moderate increase in presynaptic stimulation frequency results in plasticity (Fino et al., 2005; Ronesi and Lovinger, 2005). When indicated, the single AP during the pairing period was replaced by three APs spaced apart at $50 \mathrm{~Hz}$. Single postsynaptic APs were elicited with brief current injection through the recording electrode (1030 \pm 17 pA, 2-5 ms). Spike timing was defined as the time between EPSP onset and AP peak. In case of the pairing of an EPSP with a burst of three APs, spike timing was defined as the time between EPSP onset and peak of AP closest in time to the EPSP. After the pairing period, EPSPs were recorded for 30-40 min. For every single recording, the amount of plasticity was measured as the percentage change of the average EPSP amplitude 20-30 min after pairing when compared with the average EPSP amplitude in the $10 \mathrm{~min}$ before pairing. Paired-pulse ratio (PPR) was calculated before and 20-30 min after EPSP-AP pairing by applying double pulses at an interstimulus interval of $50 \mathrm{~ms}$ (repeated at $0.067 \mathrm{~Hz}$ ) and dividing the mean of the second response by the mean of the first response (Kim and Alger, 2001).

Histochemistry and chemicals. Slices were fixed overnight in 4\% paraformaldehyde at $4^{\circ} \mathrm{C}$, and biocytin-filled neurons were visualized with the avidin-biotin-horseradish peroxidase reaction (Vectastain Elite ABC kit; Vector Laboratories, Burlingame, CA). Chemicals were obtained from Sigma (St. Louis, MO), with the exception of D-AP-5 and CNQX (Tocris Bioscience, Bristol, UK).

Analysis and statistics. EPSP amplitude fluctuations can be expressed by the coefficient of variation, $\mathrm{CV}=\mathrm{SD} /$ mean $=((1-p) / n p)^{-2}$, which is independent of quantum size according to a simplified model of synaptic transmission ( $q$, mean synaptic response to a packet of transmitter, a quantum; $p$, the probability of release; $n$, the number of release sites) (Bekkers and Stevens, 1990; Malinow and Tsien, 1990). The ratio of the CVs before and 20-30 min after the STDP protocol were calculated. Because the average mean in the LTP control group had not reached stationarity 20-30 min after induction, we calculated the CV ratios for this group 30-40 min after induction. In addition, the ratio of squared CVs before $\left(\mathrm{CV}_{\mathrm{b}}{ }^{2}\right)$ and 20-30 min after $\left(\mathrm{CV}_{\mathrm{a}}{ }^{2}\right)$ the STDP protocol and the ratio of the mean EPSP amplitudes before $\left(\operatorname{EPSP}_{\mathrm{b}}\right)$ and 20-30 min after $\left(\right.$ EPSP $\left._{\mathrm{a}}\right)$ the STDP protocol were calculated. The relation of these two ratios to each other allows conclusions about which synaptic parameter has changed during synaptic modifications. In detail, in case of an increase of mean EPSP amplitude, the following possibilities arise: (1) $\left(\mathrm{CV}_{\mathrm{b}}{ }^{2} / \mathrm{CV}_{\mathrm{a}}{ }^{2}\right)>\mathrm{EPSP}_{\mathrm{a}} / \mathrm{EPSP}_{\mathrm{b}}$, which suggests an increase in $p$ and/or $n$; (2) $\left(\mathrm{CV}_{\mathrm{b}}{ }^{2} / \mathrm{CV}_{\mathrm{a}}{ }^{2}\right)=\mathrm{EPSP}_{\mathrm{a}} / \mathrm{EPSP}_{\mathrm{b}}$, which suggests an increase in $n$; or (3) $\left(\mathrm{CV}_{\mathrm{b}}{ }^{2} / \mathrm{CV}_{\mathrm{a}}{ }^{2}\right)=1$, which suggests an increase in $q$.

In the case of a decrease of mean EPSP amplitude, the complementary 
A
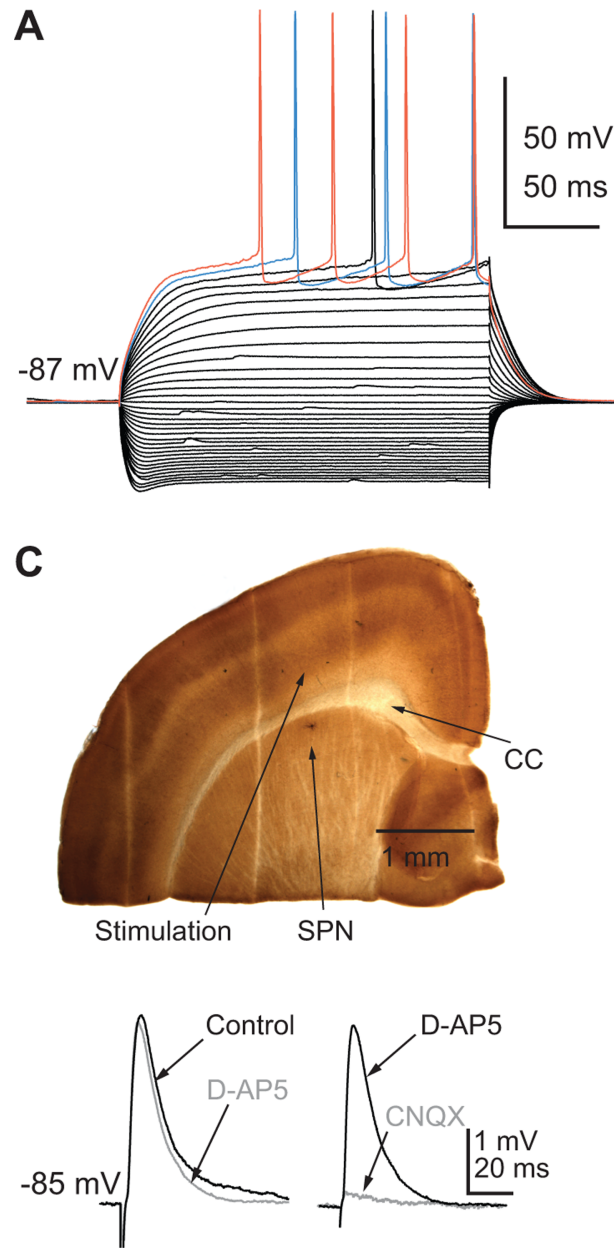

B

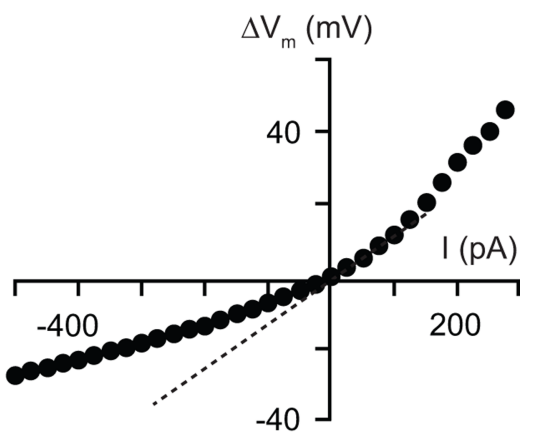

D

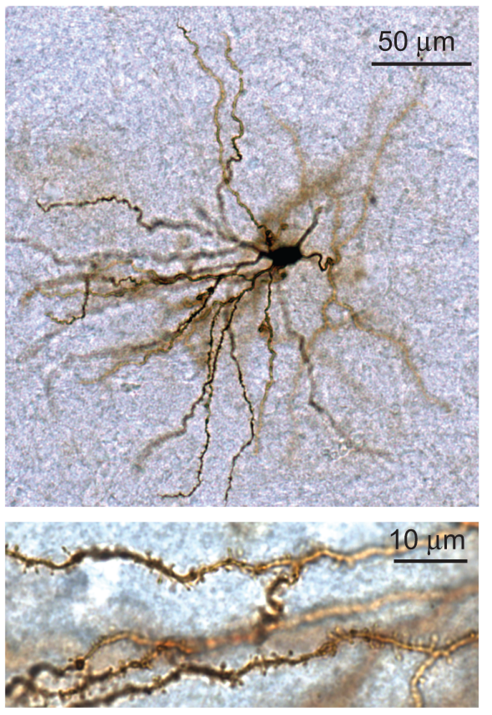

Figure 1. Experimental configuration and identification of striatal SPNs. $\boldsymbol{A}$, Single voltage traces demonstrating passive and active membrane properties of SPNs: hyperpolarized resting membrane potential, inward and outward rectification in response to subthreshold current injections (current-voltage relationship, B), and delayed spiking after suprathreshold current injection. Current injections ranged from -500 to 350 pA. C, Microphotograph of slice showing the dorsal striatum, the corpus callosum (CC), and the adjacent cortical layers. Position of stimulation electrode and recorded SPN are denoted. Composition of cortically evoked EPSPs as shown by effects of pharmacological blockers of NMDA receptors (D-AP-5, $50 \mu \mathrm{M}$ ) and AMPA/kainate receptors (CNQX, $100 \mu \mathrm{M}$ ). D, Morphology of SPN as revealed with biocytin staining; dendrites are studded with spines (bottom).

parameter changes are applicable. Because the CV ratios for control LTP were comparable between $20-30 \mathrm{~min}(0.85 \pm 0.07)$ and $30-40 \mathrm{~min}$ $(0.79 \pm 0.05)$ after induction and to allow for better comparison between groups, CV data for this group are presented in Figure $6 C$ for the 20-30 min time period.

All results were expressed as mean \pm SEM, and, unless otherwise indicated, statistical significance was assessed using an unpaired twotailed Student's $t$ test (after testing for normal distribution of data) at the significance level indicated. The grouped data for a specific STDP protocol was assessed with a paired two-tailed Student's $t$ test, whose $p$ value is always indicated together with the average EPSP percentage change. The influence of pharmacological compounds or burst protocols on induction of LTP or LTD was investigated with an unpaired one-tailed Student's $t$ test.

\section{Results}

Characteristics of recorded cells

Recordings were obtained from 142 neostriatal neurons in corticostriatal slices from 87 animals. Of these neurons, 116 showed electrophysiological properties characteristic of spiny projection neurons (Kita et al., 1985; Kawaguchi et al., 1989; Nisenbaum and Wilson, 1995) such as hyperpolarized resting membrane potential $(-83.6 \pm 0.4 \mathrm{mV} ; n=116)$, inward and outward rectification in response to hyperpolarizing and depolarizing current injection, delayed action potential discharge with respect to onset of current injection (145 \pm 4 ms spike delay; $259 \pm 11 \mathrm{pA}$ current; $n=116)$, and low input resistance (143 $\pm 7 \mathrm{M} \Omega ; n=116)$ (Fig. 1A,B) (supplemental Table 1, available at www.jneurosci.org as supplemental material). Neurons were routinely filled with biocytin and histochemically processed. Thus, all neurons included in the study were identified as SPNs by their electrophysiological parameters and morphological characteristics [extensively branching dendritic tree with several primary dendrites, higher-order dendrites were studded with spines) (Fig. 1D) (supplemental Fig. 1 and Movie, available at www. jneurosci.org as supplemental material) (Wilson, 1990)]. The remaining neurons were, based on their passive and active membrane properties and morphology (Kawaguchi, 1993; Zhou et al., 2002), identified as cholinergic interneurons $(n=7)$, fast-spiking GABAergic interneurons $(n=17)$, and low-threshold-spiking interneurons $(n=2)$ and were excluded from the present study (supplemental Table 1 and Fig. 2, available at www.jneurosci. org as supplemental material). EPSPs were elicited in SPNs located in dorsolateral striatum by extracellular stimulation of cortical layer 5 afferents (Fig. 1C) (average EPSP amplitude, $4.60 \pm 0.20 \mathrm{mV} ; n=$ 116). Because of the reversed IPSP attributable to hyperpolarized SPN resting membrane potential (Kita, 1996; Czubayko and Plenz, 2002; Tunstall et al., 2002) as well as to block possible "feedforward" GABAergic inputs (Plenz and Kitai, 1998; Koos and Tepper, 1999), all recordings were made in a $\mathrm{GABA}_{\mathrm{A}}$ receptor antagonist (picrotoxin, $50 \mu \mathrm{M}$ ). In addition, picrotoxin also blocks "feedback" interaction of GABAergic inputs from neighboring SPNs, which has been suggested to influence the time course of AP backpropagation (Plenz, 2003; Tepper et al., 2004; Bolam et al., 2006). In the current study, EPSPs were mediated by AMPA/ kainate receptor channels with negligible contribution of NMDA receptor channels (Fig. 1C) $(n=3)$ and had a single rising phase with a rise time $(2.30 \pm 0.09 \mathrm{~ms} ; n=116)$, latency $(2.75 \pm 0.08$ $\mathrm{ms} ; n=116)$, and half-width $(16.9 \pm 0.6 \mathrm{~ms} ; n=116)$ (supplemental Table 1, available at www.jneurosci.org as supplemental material) as described previously (Kawaguchi et al., 1989; Jiang and North, 1991; Walsh and Dunia, 1993; Kita, 1996; Akopian and Walsh, 2002). Together, this shows that only SPNs and evoked monosynaptic corticostriatal EPSPs were included in the present study.

\section{Corticostriatal plasticity outcome depends on spike timing} Synaptic modification of the corticostriatal pathway has been described using both HFS (100 Hz) (Calabresi et al., 1992b; Lovinger et al., 1993; Walsh and Dunia, 1993; Wickens et al., 1996; Kerr and Wickens, 2001) and single APs timed with depolarizing 
PSPs of unknown composition at an intermediate frequency $(1 \mathrm{~Hz})$ (Fino et al., 2005). Although the timing of APs in SPNs relative to synaptic activation has been shown to dictate the level of dendritic calcium (Carter and Sabatini, 2004; Kerr and Plenz, 2004) on a scale of tens of milliseconds, the effect of this timing on synaptic modification using corticostriatal EPSPs has not been tested. First, we paired EPSPs evoked by cortical stimulation with single APs with a delay of $10 \mathrm{~ms}(\Delta t=10 \mathrm{~ms} ; 60$ EPSP-AP pairings), a timing of presynaptic activation and postsynaptic APs, in which the highest levels of dendritic calcium were reported (Kerr and Plenz, 2004). The presynaptic stimulation frequency during this STDP protocol remained low $(0.1 \mathrm{~Hz})$ as in the baseline period. Timing EPSPs and APs in such a way resulted in an average increase in EPSP amplitude as determined 20-30 min after the STDP protocol $(+30 \pm 11 \% ; n=11$; $p=0.025$ ) (Fig. $2 A, C$ ). Membrane properties, such as input resistance, resting membrane potential, and current-voltage relationship, were unchanged after the STDP protocol compared with baseline (Fig. $2 A, B$ ) (for criteria, see Materials and Methods). Of these neurons, 8 of the 11 tested resulted in LTP, whereas the remaining showed no change $(n=2)$ or depression $(n=1)$ (Fig. $3 A)$. Together, this shows that the timing of single striatal APs $10 \mathrm{~ms}$ after cortical stimulation can elicit robust LTP of the corticostriatal inputs. This raised the question of whether striatal APs occurring before corticostriatal EPSPs elicit a decrease in synaptic efficacy as has been reported in multiple cortical areas (Markram et al., 1997; Feldman, 2000; Froemke et al., 2005).

\section{Corticostriatal STDP is bidirectional}

To investigate whether reversed presynaptic and postsynaptic activation leads to reversed corticostriatal plasticity, we elicited SPN APs at various times before corticostriatal EPSPs $(\Delta t=-10,-20$, and $-30 \mathrm{~ms} ; 60$ AP-EPSP pairings at a frequency of $0.1 \mathrm{~Hz}$ ). Together, these timings resulted in different plasticity outcomes, with the $\Delta t=-30 \mathrm{~ms}$ resulting in the most robust and reproducible LTD (Fig. $2 D, F)$ that was not attributable to changes in either membrane potential or input resistance (Fig. $2 D, E$ ). Although the consistent decrease in synaptic strength produced by APs $30 \mathrm{~ms}$ before the EPSP was robust $[-28 \pm 8 \%, n=12, p=0.0051$ (Fig. $2 F$ ); 9 of 12 SPNs showed LTD (Fig. 3A)], APs at less negative timings produced less consistent results. Specifically, in the other two timing cases $(\Delta t=$ -10 and $-20 \mathrm{~ms}$ ), synaptic plasticity outcomes ranged from potentiation to depression and included neurons that displayed no change (average, $-1 \pm 10 \%, n=11, p=0.749$; range, -58 to $+48 \%$; median $\pm \mathrm{SD},-3 \pm 29 \% ; \Delta t=-10$ and $-20 \mathrm{~ms}$ pooled). This
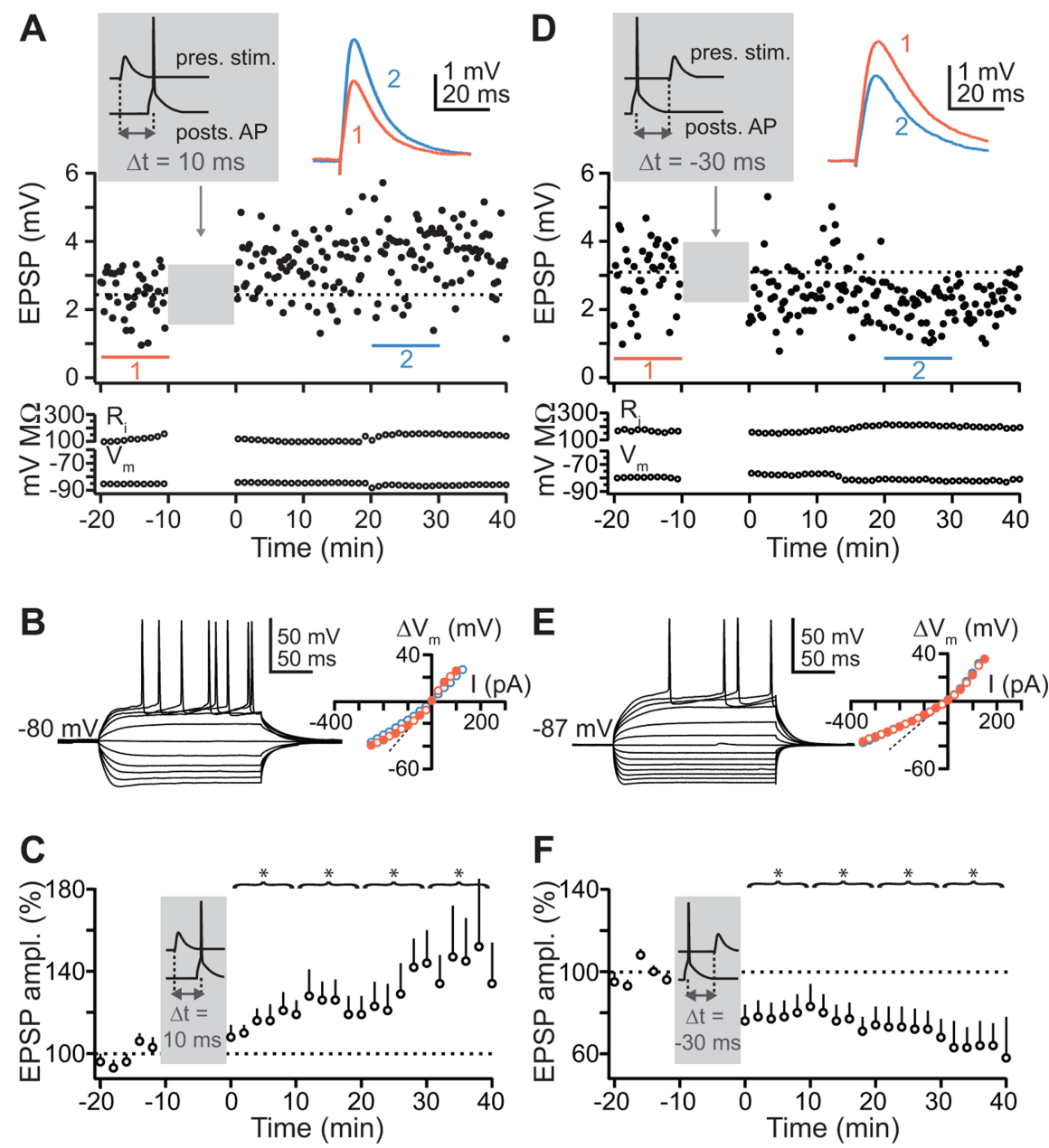

Figure 2. Spike-timing-dependent increase and decrease in corticostriatal synaptic efficacy. $\boldsymbol{A}$, Representative recording from a single SPN showing spike-timing-dependent LTP. EPSP amplitude, $R_{\mathrm{i}}$, and $V_{\mathrm{m}}$ are plotted against time. After the baseline period (red line and red EPSP trace, top right inset), stimulation of cortical afferents ("presynaptic stimulation") was followed 10 ms later by a postsynaptic AP elicited by somatic current injection (see gray inset, $\Delta t=10 \mathrm{~ms}$ ). Dashed line indicates average of EPSP amplitudes before the STDP protocol. In the post-pairing time, a 45\% increase in EPSP amplitudes was observed $(p<0.0001$, blue line and blue trace, top right inset). EPSP traces (top right inset) are averages of all EPSPs recorded in the time indicated by the red and blue lines, respectively. $\boldsymbol{B}$, Voltage responses to hyperpolarizing and depolarizing current injections ( -250 to 175 pA) show inward and outward rectification typical for an SPN (left), and the current-voltage relationship was similar before (red circles) and after (blue circles) EPSP-AP pairing (right; filled circles correspond to voltage responses shown in the left; for simplicity, voltage responses for open circles were not shown in the left). C, Average of all recordings from SPNs that underwent the EPSP-AP pairing with a time delay of $\Delta t=10 \mathrm{~ms}(n=11)$. Brackets indicate the time when EPSP amplitudes (in percentage of control) were significantly increased compared with baseline $\left({ }^{*} p<0.05\right)$. For significance tests, EPSP amplitudes were binned in 10 min intervals. $\boldsymbol{D}$, Representative recording from a single SPN showing spike-timing-dependent LTD. After the baseline period (red line and red trace, top right inset), a somatically induced AP was followed by an EPSP with a delay of $\Delta t=-30 \mathrm{~ms}$ (see gray inset). This resulted in a decrease of EPSP amplitudes by $34 \%$ ( $p<0.0001$, blue line and blue trace, top right inset). $\boldsymbol{E}$, Voltage responses to hyperpolarizing and depolarizing current injections ( -375 to $275 \mathrm{pA}$ ) are typical for an SPN (left), and the currentvoltage relationship is identical before (red circles) and after (blue circles) AP-EPSP pairing. $F$, Average of all recordings from SPNs that underwent the AP-EPSP pairing with a delay of $\Delta t=-30 \mathrm{~ms}(n=12)$. Brackets indicate the time when EPSP amplitudes were significantly decreased compared with baseline $\left({ }^{*} p<0.05\right)$.

shows that, like with STDP reported in cortical layer 5 neurons, which also innervate the striatum, changes in timing of APs relative to the EPSP change synaptic efficacy bidirectionally (Markram et al., 1997; Sjostrom et al., 2001). In addition, these results show that induction of consistent corticostriatal LTD is only observed when the AP-EPSP delay time is at least $30 \mathrm{~ms}$.

\section{AP bursts do not increase plasticity}

Several cortical studies have described that bursts of APs are required to induce spike-timing-dependent LTP, but the pairing of a single AP with an EPSP is sufficient to induce LTD (Magee and 

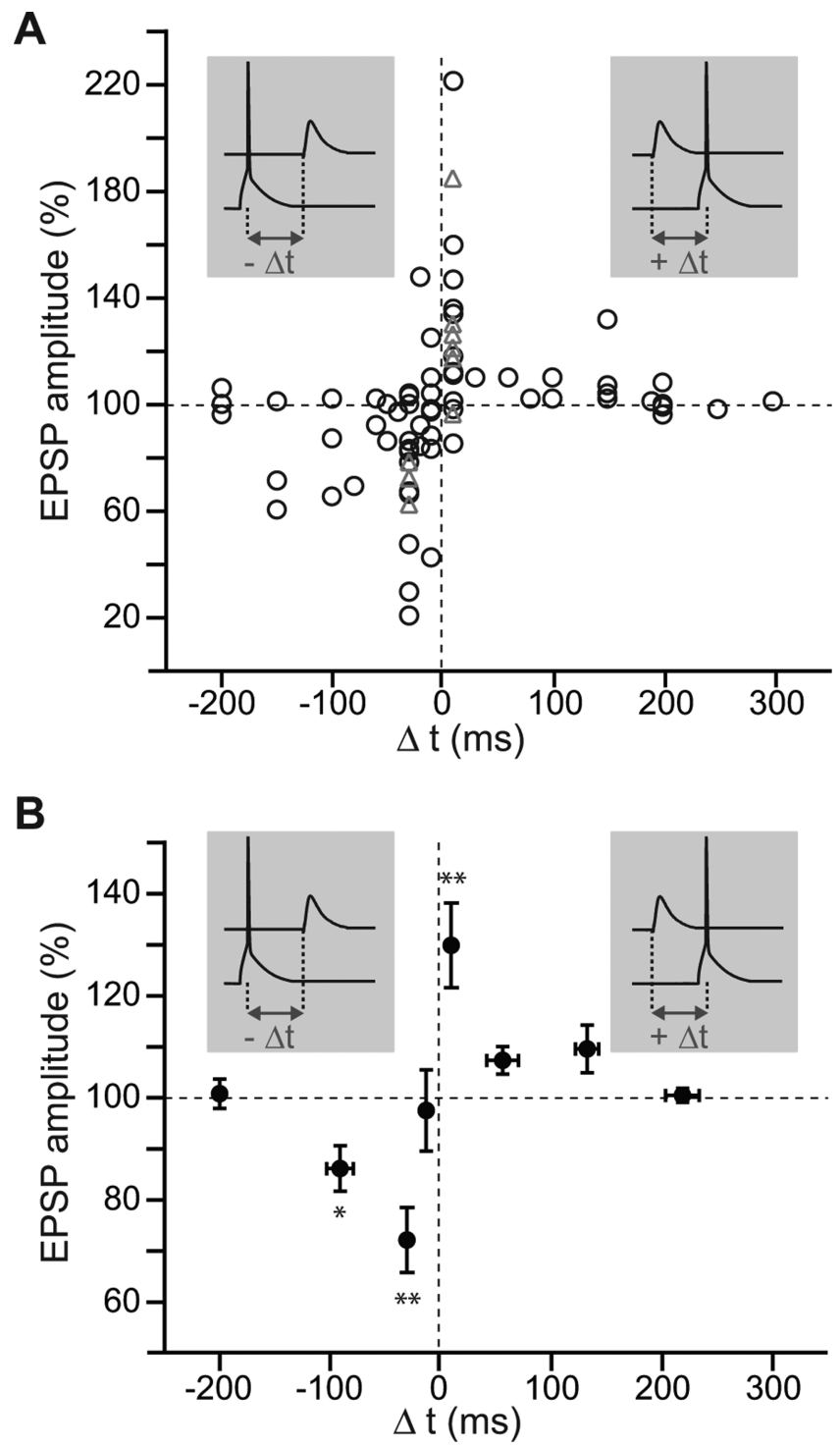

Figure 3. The spike-timing window for the corticostriatal pathway. A, Plot of all single experiments with positive $\Delta t$ values (EPSP leads the AP, see right gray inset) and with negative $\Delta t$ values (EPSP follows the AP, see left gray inset). The respective EPSP-AP timings are plotted against the resulting change in EPSP amplitude (in percentage of control). Change in EPSP amplitude was calculated by comparing the mean EPSP amplitude from 20 to 30 min after the STDP protocol to the mean EPSP amplitude from the $10 \mathrm{~min}$ before the STDP protocol. Circles depict experiments in which one AP was paired with an EPSP $(n=65)$; gray triangles depict experiments in which an AP burst was paired with an EPSP $(n=9)$. B. Average of all EPSP-AP timings and effect on synaptic strength from above. Data was grouped according to EPSP-AP timing during the STDP protocol, and a two-tailed paired $t$ test was performed to assess significance $\left.{ }^{*} p<0.05 ;{ }^{* *} p<0.01\right)$.

Johnston, 1997; Nevian and Sakmann, 2006; Wittenberg and Wang, 2006). To investigate whether replacing single APs by bursts of APs in the STDP protocol reduces the variability of synaptic potentiation or increases the amount of synaptic potentiation, we conducted a set of experiments in which an EPSP was followed by a burst of APs [three APs (3AP) at $50 \mathrm{~Hz}$, delayed 10 ms after EPSP], a burst pairing protocol similar to previous cortical studies (Magee and Johnston, 1997; Meredith et al., 2003; Nevian and Sakmann, 2006). In the present study, the burst protocol induced almost exactly the same change in synaptic strength, and outcomes displayed similar variability as seen with the single AP protocol [single AP LTP, $+30 \pm 11 \%, n=11$ compared with baseline $p=0.025, \mathrm{CV}=0.290$ (Fig. $3 A$, circles) vs 3 AP LTP, $+30 \pm 12 \%, n=6$ compared with baseline $p=$ $0.048, \mathrm{CV}=0.229$ (Fig. $3 A$, gray triangles); comparison between groups, $p=0.4937$ ]. Similarly, replacing the LTD inducing single AP protocol (AP-EPSP $\Delta t=-30 \mathrm{~ms}$ ) with the burst protocol did not significantly change the amount of plasticity induced $[-29 \pm$ $5 \%, n=3$ (Fig. $3 A$, gray triangles), $p<0.001$ for each single recording, comparison between single AP LTD and 3AP LTD, $p=0.467]$. Thus, the timing of EPSPs with single APs is as efficient in inducing synaptic plasticity as the timing of EPSPs with AP bursts. No significant correlation between initial EPSP size and amount of synaptic modification was present (Pearson's correlation coefficient, $r=0.04, p=0.88$ and $r=0.12, p=0.67$, LTP and LTD respectively; data not shown). Thus, the number of synapses activated or the initial efficacy of the synapses does not seem to affect the ability to induce AP-timing-based synaptic modification of the corticostriatal pathway.

\section{Asymmetry of the spike-timing window}

To investigate how changes in the timing of striatal APs relative to cortical inputs affect corticostriatal synaptic efficacy, we incrementally increased the interval between the AP and EPSP, for both positive $\Delta t$ values (EPSP followed by AP) and negative $\Delta t$ values (AP followed by EPSP). On average, as the time between the AP and EPSP increased, the change in synaptic efficacy decreased (Fig. $3 A$ shows modifications in synaptic strength for single recordings; $n=74$ ). For statistical evaluation of plasticity outcome for different EPSP-AP timing delays, the data were pooled into eight groups (Fig. $3 B$ ). For the group in which an EPSP was closely followed by an AP $(\Delta t=10 \mathrm{~ms})$, a significant increase in synaptic strength was observed $(p=0.0024 ; n=17)$, and, likewise, a significant decrease in synaptic strength was observed for the group, in which the AP led the EPSP by $30 \mathrm{~ms}(\Delta t=$ $-30 \mathrm{~ms} ; p=0.0006 ; n=15)$ and for the group in which $\Delta t$ was -150 to $-40 \mathrm{~ms}(p=0.0104 ; n=12)$. Together, this shows that, although the spike-timing window for increases in synaptic strength was narrow and close to $0 \mathrm{~ms}$, the spike-timing window for decreases in synaptic strength was broad.

\section{Dopamine receptor activation is necessary for spike-timing-based plasticity}

We next tested the role of dopamine receptors in striatal STDP. In the presence of the dopamine $\mathrm{D}_{1} / \mathrm{D}_{5}$ receptor antagonist $(\mathrm{SCH}-$ 23390, $10 \mu \mathrm{M}$ ), LTP was not induced using the STDP protocol that normally produced LTP in control conditions $(\Delta t=10 \mathrm{~ms}$; $+2 \pm 4 \% ; n=9 ; p=0.8079$ ) (Fig. $4 A-C$ ). Dopamine $\mathrm{D}_{1} / \mathrm{D}_{5}$ receptor antagonism also prevented synaptic depression when the EPSP followed the AP by $30 \mathrm{~ms}$ during the STDP protocol $(\Delta t=-30 \mathrm{~ms} ;-3 \pm 9 \% ; n=7 ; p=0.7343)$ (Fig. $4 D-F)$. These outcomes were not attributable to changes in either active or passive membrane properties compared with control conditions (Table 1).

To test for the role of dopamine $\mathrm{D}_{2}$ receptors in corticostriatal STDP, we next paired APs and EPSPs in the presence of the dopamine $\mathrm{D}_{2}$ receptor-specific antagonist $(S)-(-)$ sulpiride $(10$ $\mu \mathrm{M})$. In the presence of sulpiride, single APs after EPSPs $(\Delta t=10$ $\mathrm{ms})$ produced robust potentiation of synaptic strength observed $20-30$ min after induction $(+32 \pm 12 \% ; n=8 ; p=0.0290)$ (Fig. $5 A-C)$ that was not significantly different from controls $(p=$ 0.4433). Reversal of the AP and EPSP order during the STDP protocol (pairing delay, $\Delta t=-30 \mathrm{~ms}$ ) resulted in depression of EPSP amplitudes $(-18 \pm 12 \% ; n=5 ; p=0.037 ; 20-30$ min after induction) (Fig. $5 D-F)$ that was also not significantly different 
from controls $(p=0.2490)$. Despite the lack of dopamine $\mathrm{D}_{2}$ receptor antagonist influence over the final plasticity outcome, blocking the $\mathrm{D}_{2}$ receptors influenced the temporal structure of plasticity. Onset of potentiation was more immediate in the first $10 \mathrm{~min}$ after the STDP protocol compared with controls $(+29 \pm 16 \%$ in sulpiride vs $+14 \pm 7 \%$ control; comparison between groups, $p=0.0035$, paired $t$ test) (Fig. 5C). Conversely, the average onset of depression was delayed, meaning that, in the first $10 \mathrm{~min}$ after the STDP protocol, no significant depression was observed [ $-6 \pm 13 \%$ in sulpiride vs control $-22 \pm 8 \%$ (Fig. $5 F$ ); comparison between groups, $p=0.022$, paired $t$ test]. Together, these results show a distinct role of dopamine receptor activation in both spike-timing-based LTP and LTD. Specifically, dopamine $D_{1} / D_{5}$ receptor activation is necessary for both LTP and LTD induction and dopamine $\mathrm{D}_{2}$ receptor activation changes the temporal structure but not the long-term outcome of corticostriatal STDP.

\section{Corticostriatal STDP is NMDA dependent}

Although NMDARs are involved in strengthening corticostriatal synapses after high-frequency presynaptic stimulation (Calabresi et al., 1992a), they were reported to play no role in the depression of corticostriatal synapses (Calabresi et al., 1992b; Walsh, 1993; Choi and Lovinger, 1997b). To test for the role of NMDARs in corticostriatal STDP, we performed experiments in the presence of the NMDAR blocker D-AP-5 (50 $\mu \mathrm{M})$ (Fig. 6A,B). LTP was not induced when NMDARs were blocked $(\Delta t=10 \mathrm{~ms} ;+3 \pm 9 \% ; n=7 ; p=$ 0.7359 ; compared with control group, $p=$ 0.0278 ). In contrast to the HFS studies, LTD induction was blocked in the presence of D-AP-5. Instead, average synaptic strength showed a slight but not significant increase after the STDP protocol that induced LTD in control conditions $(\Delta t=$ $-30 \mathrm{~ms} ;+11 \pm 11 \% ; n=5 ; p=0.4053$; compared with control group, $p=0.0088$ ) (Fig. $6 A, B$ ). Together, this shows that NMDAR activation is necessary for both LTP and LTD induction using spike-timing-based protocols and suggests that corticostriatal STDP depends not only on dopamine receptors but also on NMDA receptors.

\section{Spike-timing-dependent LTP and LTD use different synaptic expression mechanisms}

Plasticity can arise from various mechanisms: changes in neurotransmitter release, changes in the number of release sites, changes in postsynaptic receptor number and responsiveness, or changes in the number of silent synapses (Malenka and Nicoll, 1999; Sanes and Lichtman, 1999). To identify mechanisms that Fig. 2F).
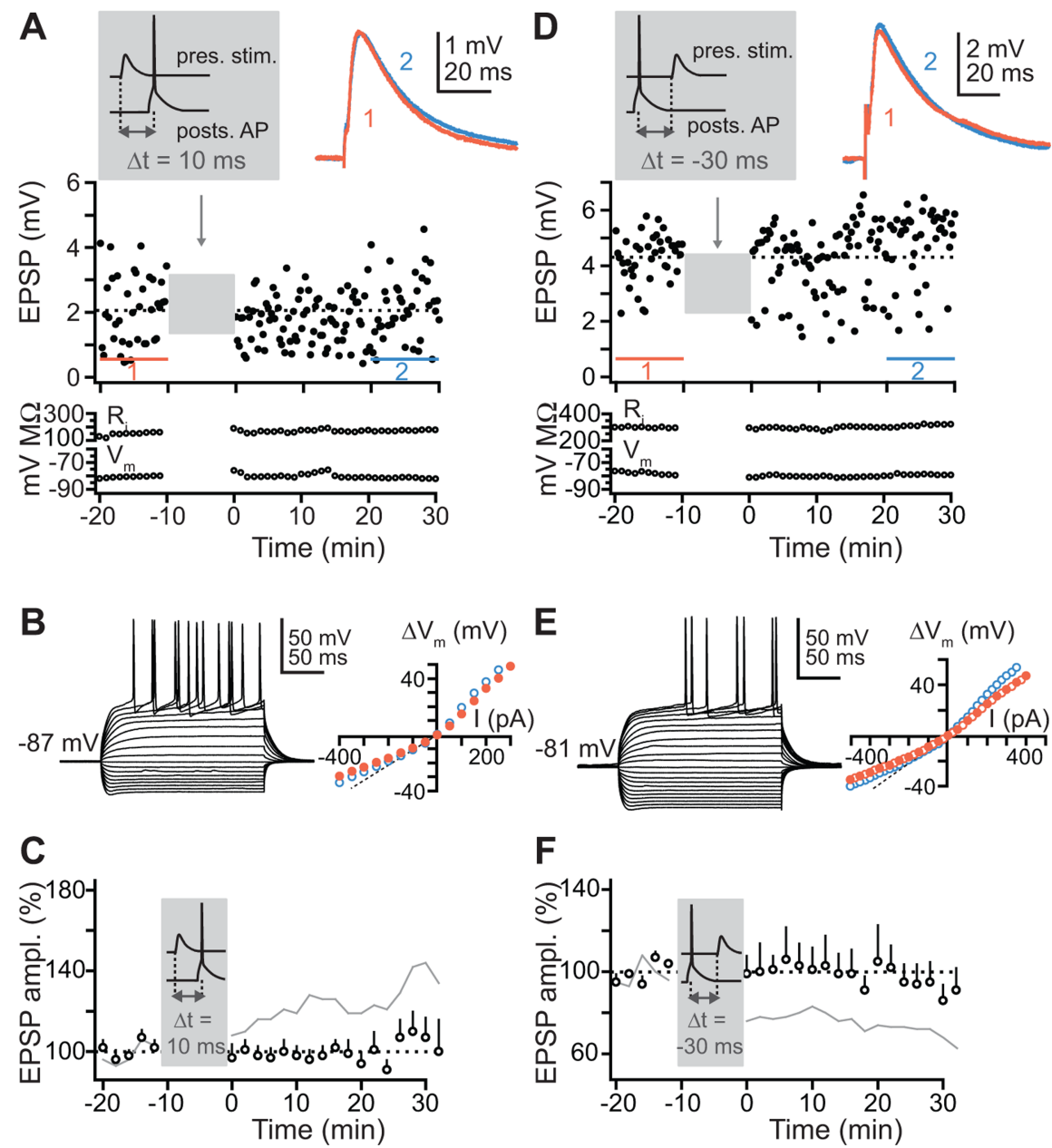

Corticostriatal STDP depends on dopamine $D_{1} / D_{5}$ receptor activation. $A$, Representative recording in the presence of

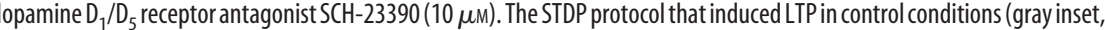
$\Delta t=10 \mathrm{~ms}$ ) had no effect on synaptic strength; EPSPs after the STDP protocol (blue trace) were unchanged compared with EPSPS (b) STDP protocol ( $\Delta t=10 \mathrm{~ms}$ ). Exemplary single traces were STDP protocol with a delay of $\Delta t=10 \mathrm{~ms}$ between EPSP and AP was applied $(n=9)$. For comparison, gray line 作

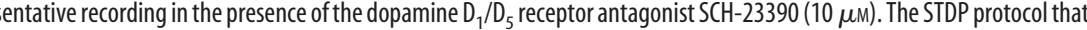
列 the average EPSP change in response to the respective STDP protocol ( $\Delta t=-30 \mathrm{~ms}$ ) under control conditions (same data as in

underlie corticostriatal STDP, we calculated the PPR and CV of EPSP amplitudes before and after the respective STDP protocols (Choi and Lovinger, 1997a; Ronesi and Lovinger, 2005). If corticostriatal spike-timing protocols affected release probability, we would expect a concomitant change in the PPR attributable to changes in vesicle availability for the second pulse (Zucker, 1989). The initial CV and PPR values were not different between control and the different drug conditions with the exception of the initial PPR in sulpiride (control, $1.27 \pm 0.07$; sulpiride, $0.91 \pm 0.08 ; p=$ $0.03)$. After both STDP protocols $(\Delta t=10 \mathrm{~ms}$ and $\Delta t=-30 \mathrm{~ms}$, respectively) and under all drug conditions, the PPR was not significantly changed (Fig. 6C, top; D-AP-5 data not shown), suggesting that synaptic efficacy changes recorded after STDP pro- 
Table 1. Comparison of SPN properties in control conditions and in the presence of SCH-23390, sulpiride, or D-AP-5

\begin{tabular}{|c|c|c|c|c|}
\hline & Control $(n=74)$ & SCH-23390 $(n=16)$ & Sulpiride $(n=14)$ & D-AP-5 $(n=12)$ \\
\hline $\operatorname{RMP}(\mathrm{mV})$ & $-83.5 \pm 0.4$ & $-83.4 \pm 1.3$ & $-82.4 \pm 0.7$ & $-85.4 \pm 0.7$ \\
\hline Input resistance (M $\Omega$ ) & $139 \pm 10$ & $137 \pm 9$ & $164 \pm 22$ & $138 \pm 15$ \\
\hline AP amplitude (mV) & $74.8 \pm 1.3$ & $76.8 \pm 2.5$ & $74.5 \pm 2.7$ & $77.3 \pm 3.0$ \\
\hline AP threshold (mV) & $-33.9 \pm 0.8$ & $-35.5 \pm 1.4$ & $-33.3 \pm 2.0$ & $-35.9 \pm 1.8$ \\
\hline AP half-width (ms) & $1.04 \pm 0.02$ & $1.05 \pm 0.03$ & $1.06 \pm 0.11$ & $1.12 \pm 0.04$ \\
\hline AP delay (ms) & $147 \pm 5$ & $155 \pm 8$ & $136 \pm 8$ & $138 \pm 11$ \\
\hline AHP amplitude (mV) & $-12.0 \pm 0.3$ & $-10.4 \pm 0.8$ & $-12.4 \pm 0.8$ & $-10.5 \pm 0.6$ \\
\hline AHP time to peak (ms) & $14.5 \pm 1.1$ & $13.7 \pm 1.8$ & $12.8 \pm 2.1$ & $14.5 \pm 1.5$ \\
\hline I inj. threshold to elicit AP (pA) & $265 \pm 16$ & $240 \pm 26$ & $250 \pm 23$ & $266 \pm 31$ \\
\hline \# APs at threshold & $1.2 \pm 0.1$ & $1.3 \pm 0.1$ & $1.2 \pm 0.1$ & $1.2 \pm 0.1$ \\
\hline \# APs 50 pA above threshold & $3.1 \pm 0.2$ & $3.3 \pm 0.3$ & $2.9 \pm 0.8$ & $3.0 \pm 0.3$ \\
\hline EPSP amplitude (mV) & $4.80 \pm 0.29$ & $4.68 \pm 0.60$ & $4.02 \pm 0.29$ & $4.09 \pm 0.56$ \\
\hline EPSP $20-80 \%$ RT (ms) & $2.10 \pm 0.13$ & $2.33 \pm 0.12$ & $2.51 \pm 0.23$ & $2.39 \pm 0.17$ \\
\hline EPSP latency (ms) & $2.58 \pm 0.10$ & $2.10 \pm 0.17$ & $2.93 \pm 0.18$ & $2.71 \pm 0.15$ \\
\hline EPSP half-width (ms) & $15.3 \pm 0.7$ & $18.5 \pm 1.0^{*}$ & $19.3 \pm 1.6^{*}$ & $14.8 \pm 0.4$ \\
\hline PPR & $1.27 \pm 0.07$ & $1.06 \pm 0.12$ & $0.91 \pm 0.08^{*}$ & $1.15 \pm 0.12$ \\
\hline
\end{tabular}

Data are mean \pm SEM $\left({ }^{*} p<0.05\right)$. Time-to-peak and amplitude of afterhyperpolarization (AHP) were measured from AP threshold. I inj., Current injection required to elicit APs; \#, number of obtained APs; RT, rise time. AP delay was determined with respect to onset of current injection.

tocols were not attributable to changes in transmitter release but rather to a different synaptic mechanism.

To further investigate this potential synaptic mechanism, we next analyzed changes in CV of EPSPs after the respective STDP protocols. According to quantal theory, synaptic transmission is described by three parameters: the average amplitude of the postsynaptic response to a packet of transmitter (quantal size $q$ ), the number of release sites $n$, and the release probability $p$ (Del Castillo and Katz, 1954; Bekkers and Stevens, 1990; Faber and Korn, 1991; Bekkers, 1994; Malenka and Nicoll, 1999). Theoretical models describing synaptic transmission and also direct experimental manipulation of synaptic parameters have suggested that a change in $\mathrm{CV}$ without a concomitant change in PPR reflects changes in $n$ or the number of active synapses, whereas a change in PPR and at the same time a change in CV reflects changes in $p$; conversely, an unchanged CV and PPR are thought to imply a change in $q$ (Bekkers and Stevens, 1990; Malinow and Tsien, 1990; Manabe et al., 1993; Choi and Lovinger, 1997a; Malenka and Nicoll, 1999; Sola et al., 2004), although alternative interpretations exist (Faber and Korn, 1991).

After the spike-timing protocol with a time delay of $\Delta t=10$ $\mathrm{ms}, \mathrm{CV}$ ratios (after/before) were significantly decreased, except for the D-AP-5 group (Fig. 6C, bottom; D-AP-5 data not shown) (control, $0.79 \pm 0.05, p=0.008$; SCH-23390, $0.91 \pm 0.03, p=$ 0.030; sulpiride, $0.70 \pm 0.08, p=0.0156$; D-AP-5, $1.17 \pm 0.09$, $p=0.143$, paired $t$ test). Furthermore, a strong correlation existed between synaptic change and CV change after the STDP protocol (all recordings with $\Delta t=10 \mathrm{~ms} ; n=40$; Pearson's $r=$ $-0.507 ; p=0.0008)$, implying that the observed effect of the STDP protocol on CV values was indeed underlying plasticity. Together, this suggests that an increase in the number of release sites $n$ or an increase in the number of active synapses is the most likely primary potentiation mechanism. After the STDP protocol with a delay of $\Delta t=-30 \mathrm{~ms}$, no significant changes in $\mathrm{CV}$ were observed except for experiments performed in sulpiride (1.51 \pm $0.19 ; p=0.035$, paired $t$ test), indicating that here either $n$ was decreased or synapses became inactive, whereas in controls the plasticity mechanism involved a postsynaptic change in $q$ (Fig. $6 C)$.

In summary, similar mechanisms underlie potentiation in control conditions and under $\mathrm{D}_{2}$ antagonism (increase in $n$ or activation of silent synapses), whereas the mechanisms for de- pression differ between control conditions (reduced quantum size $q$ ) and $\mathrm{D}_{2}$ antagonism (decrease in $n$ or silencing of synapses).

\section{Discussion}

Role of a single spike in inducing corticostriatal plasticity

This study shows that single APs in SPNs, when closely timed with corticostriatal afferent activation, induce robust synaptic plasticity in SPNs, and this STDP is dependent on dopamine $\mathrm{D}_{1} / \mathrm{D}_{5}$ and NMDA receptor activation. The direction and extent of this plasticity is determined by the exact timing between postsynaptically induced AP and EPSP; synaptic strength is maximally enhanced when cortically evoked EPSPs lead a spike by 10 ms, whereas synaptic strength is maximally depressed when EPSPs follow a spike by $30 \mathrm{~ms}$. We also show that the corticostriatal STDP window is asymmetrical, with the plasticity window being broader when EPSPs follow APs and narrower when APs follow EPSPs. The timing window reported in the present study is in agreement with intracortical STDP findings (Bi and Poo, 1998; Feldman, 2000; Sjostrom et al., 2001; Nevian and Sakmann, 2004; Froemke et al., 2005) but in contrast to a recent striatal study that found the timing window reversed (Fino et al., 2005). There are two differences between the study by Fino et al. and the present study that may provide a potential explanation. First, in the present study, $\mathrm{GABA}_{\mathrm{A}}$ transmission was blocked to isolate the excitatory glutamatergic corticostriatal projection as evoked PSPs in SPNs contain depolarizing IPSPs and EPSPs (Kita, 1996; Czubayko and Plenz, 2002; Tunstall et al., 2002). These GABAergic IPSPs arise from fast-spiking and low-threshold-spiking interneurons (Koos and Tepper, 1999; Koos et al., 2004), as well as surrounding SPNs (Czubayko and Plenz, 2002; Tunstall et al., 2002) and have been shown to alter AP timing (Koos and Tepper, 1999) and are proposed to modify backpropagating APs in SPNs (Plenz, 2003; Tepper et al., 2004; Bolam et al., 2006). Second, our study focused exclusively on investigating the effects of timing EPSPs with APs at the corticostriatal synapse. We therefore avoided increasing presynaptic stimulation frequency during the STDP protocol, which introduces an additional factor that has been shown to confound both the spike-timing window and the plasticity direction in other brain areas (Sjostrom et al., 2001; Tzounopoulos et al., 2004; Wittenberg and Wang, 2006). Reversed synaptic plasticity has been shown in vitro in a few hippocampal studies in which NMDAR activation was reduced 
(Cummings et al., 1996; Nishiyama et al., 2000), but STDP in the intact mammalian cortex follows standard STDP rules (Jacob et al., 2007).

Together, the present study findings suggest that, although SPN backpropagating APs are capable of "selecting" activated synapses with high temporal precision, dopamine receptor activation is required for the timed presynaptic and postsynaptic activity to induce synaptic plasticity. Although dopamine has often been described as acting on timescales of seconds to minutes (Louilot et al., 1986; Abercrombie et al., 1989; Young et al., 1992; Schultz, 2002; Arbuthnott and Wickens, 2007), we show that dopamine receptor activation opens a window for fast temporal scale events on the order of milliseconds (APs and EPSPs) to exert synaptic changes as has been proposed previously (Wickens et al., 1996; Schultz, 2002; Arbuthnott and Wickens, 2007). Because all three factors, action potential, synaptic activation, and dopamine receptor activation, are required for both striatal spiketiming-dependent LTP and LTD, this potentially allows dopamine to select both active neurons and active synapses in the striatum and subsequently increase and decrease synaptic strength. Last, we show that changes in synaptic strength can be based on ongoing sparse activity and are not reliant on massive, focused activity that is usually associated with HFS protocols but rarely recorded in vivo. In accordance with our findings, theoretical frameworks of striatal function suggest that dopamine can thus "prioritize" between competing synaptic inputs to striatal SPNs and ensure the influence of "prioritized" inputs on basal ganglia output (Montague et al., 1996; Schultz, 2002; Montague et al., 2004; Arbuthnott and Wickens, 2007; Costa, 2007).

In the striatum, dopamine is present in low nanomolar concentrations in vivo (Herrera-Marschitz et al., 1996) and in vitro (Kawagoe et al., 1992; Zhou et al., 2001; Partridge et al., 2002). These concentrations are thought to tonically activate only the dopamine $\mathrm{D}_{2}$ receptors attributable to their enhanced dopamine affinity compared with dopamine $\mathrm{D}_{1}$ receptors (Richfield et al., 1989). Our results show that dopamine $\mathrm{D}_{2}$ receptor activation is not required for corticostriatal STDP, but dopamine $\mathrm{D}_{1}$ receptor activation is required. The phasic activation of the dopamine $D_{1}$ receptors presumably is attributable to increases in dopamine concentration that have been demonstrated in vitro using stimulation of cortical afferents similar to that used in the present study (Onn et al., 2000; Partridge et al., 2002; Bamford et al., 2004; David et al., 2005). These dopamine increases have been suggested to originate from either glutamate spillover to dopaminergic terminals or current spread from the stimulation site directly activating dopaminergic fibers (Herdon et al., 1987; Bull et al., 1990; Desce
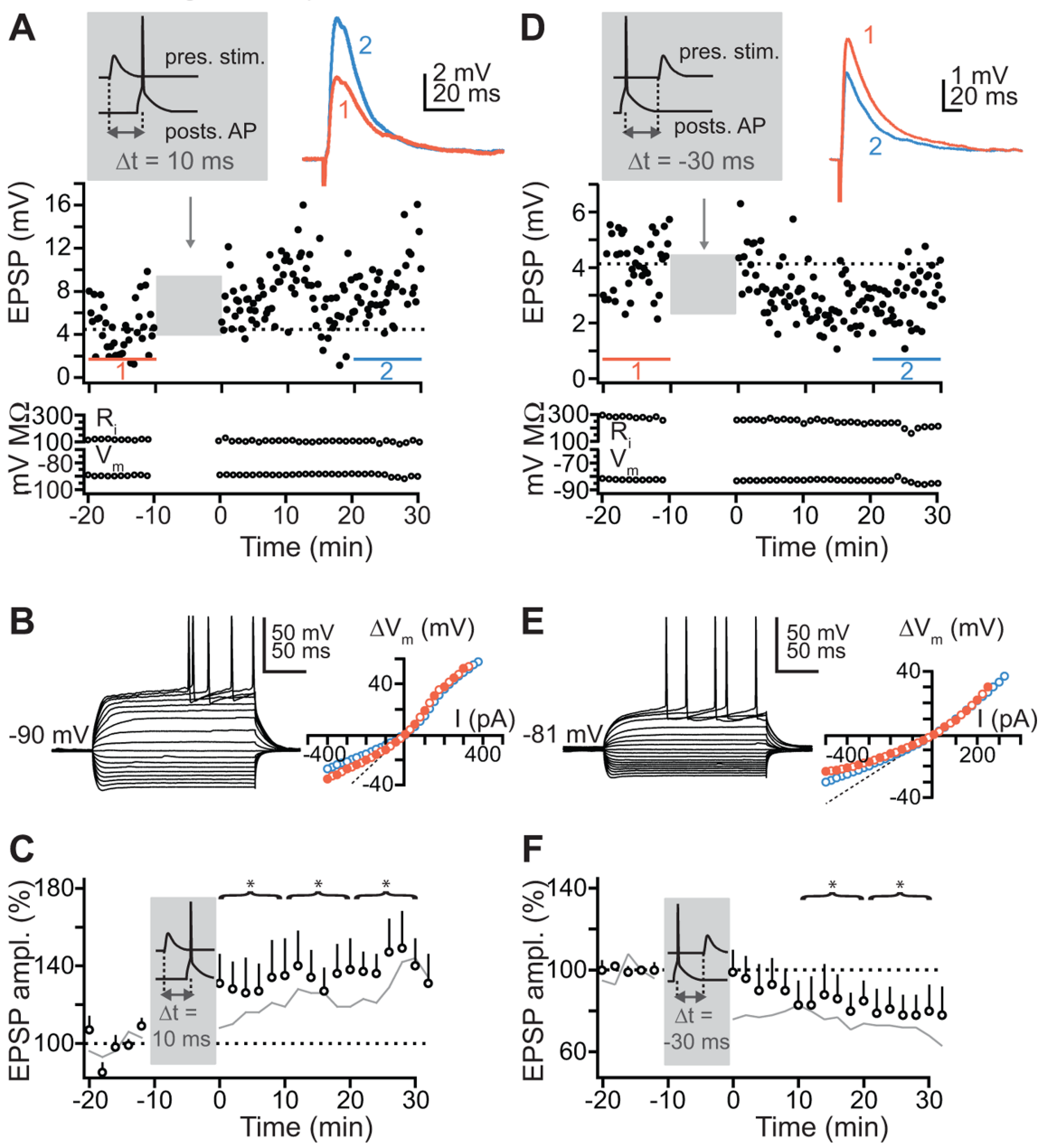

Figure 5. Corticostriatal STDP is modulated by dopamine $D_{2}$ receptor activation. $A$, Representative recording from an SPN. The antagonist sulpiride $(10 \mu \mathrm{M})$. B, Current-voltage relationship was unchanged before (red) and after (blue) the STDP protocol. explary single traces were obtained in response to current injections ranging from -400 to $400 \mathrm{pA}$. C, Average of all recordings onset of significant changes in EPSP size are indicated by brackets above traces $\left({ }^{*} p<0.05\right)$. Gray line depicts control condition with no $D_{2}$ antagonist. $D$, Representative recording from an SPN. The STDP protocol that induced LTD in control conditions $(\Delta t=$ $-30 \mathrm{~ms}$ ) also induced LTD in the presence of the $\mathrm{D}_{2}$ dopamine receptor antagonist sulpiride $(10 \mu \mathrm{M})$. $\boldsymbol{E}$, Current-voltage to current injections ranging from -500 to $325 \mathrm{pA}$. $\boldsymbol{F}$, Average of all recordings in the presence of sulpiride in which the STDP protocol with a delay of $\Delta t=-30 \mathrm{~ms}$ between EPSP and AP was applied $(n=5)$. The onset of significant changes in EPSP size are indicated by brackets above traces $\left({ }^{*} p<0.05\right)$. Gray line depicts control condition with no $D_{2}$ antagonist.

et al., 1992; Calabresi et al., 1995; Partridge et al., 2002; David et al., 2005).

Moreover, phasic dopamine concentration increases attributable to reward-related firing of substantia nigra dopaminergic neurons (Chergui et al., 1994; Dugast et al., 1994; Schultz, 2002) are also seen in the striatum in vivo. Although dopamine $\mathrm{D}_{2}$ receptors were not essential for corticostriatal STDP, we found that blocking dopamine $\mathrm{D}_{2}$ receptors initially facilitated LTP and delayed LTD; therefore, dopamine $\mathrm{D}_{2}$ receptor activation seems to have an initially inhibitory influence on spike-timing-dependent LTP and an initially facilitating influence on spike-timingdependent LTD without having an effect on the final extent of plasticity.

Because the exact location and distribution of striatal dopamine receptor subtypes is not fully understood (Gerfen et al., 1990, 1995; Gerfen, 1992; Sesack et al., 1994; Bergson et al., 1995; 
A
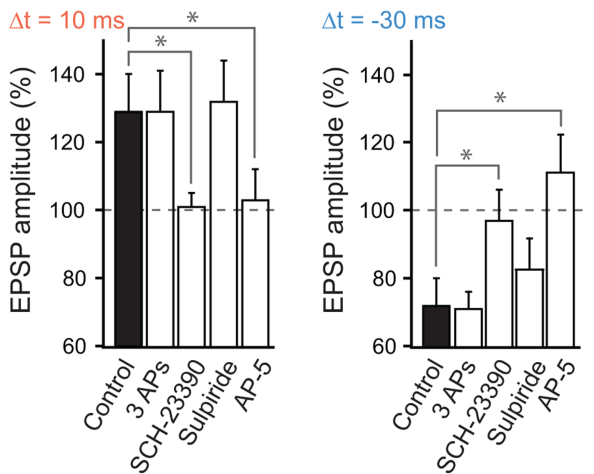

B

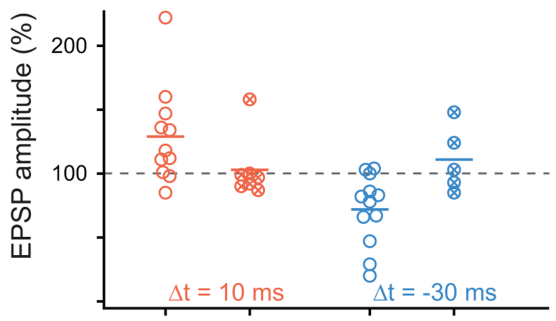

Control AP-5 Control AP-5
C
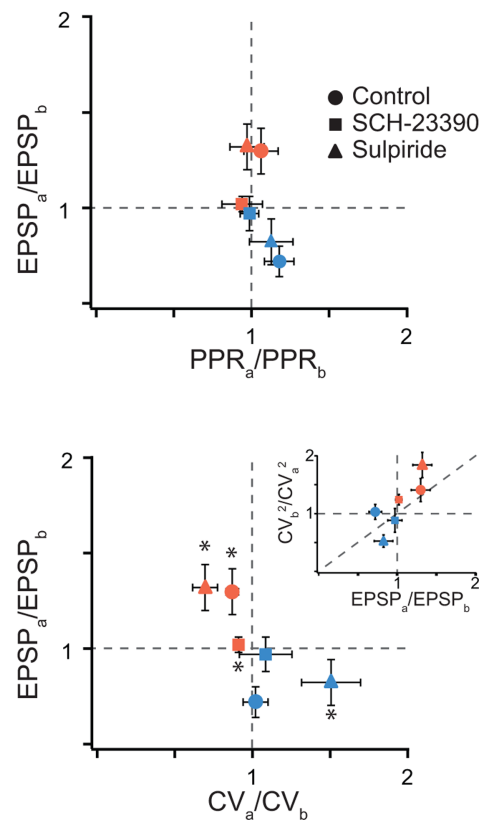

Figure 6. $A$, Comparison of two STDP protocols ( $\Delta t=10 \mathrm{~ms}$ and $\Delta t=-30 \mathrm{~ms}$ between EPSP and AP, respectively) and the resulting amount of plasticity (EPSP amplitude in percentage of control) in control conditions and in the presence of SCH-23390, sulpiride, and D-AP-5. Diagram also contains dataset in which the STDP protocol contained an AP burst. Bars represent mean \pm SEM. For statistical tests, EPSP changes 20-30 min after application of the respective STDP protocol were compared between groups (one-tailed Student's $t$ test, ${ }^{*} p<0.05$ ). B , Plot of single experiments using STDP protocols $(\Delta t=10 \mathrm{~ms}$ and $\Delta t=-30$ $\mathrm{ms}$, respectively) in control conditions (open circles) and in D-AP-5 (50 $\mu \mathrm{M}$, crossed circles). Bars show the respective group averages. C, Analysis of PPR and CV of EPSPs. Top, Analysis of paired pulse ratio before $\left(\mathrm{PPR}_{\mathrm{b}}\right)$ and after $\left(\mathrm{PPR}_{\mathrm{a}}\right)$ the respective STDP protocols. Same cells and experimental conditions as in $A$. PPRs were plotted against the ratio of EPSPs after (EPSP) and before $\left(\right.$ EPSP $_{\mathrm{b}}$ ) the respective STDP protocols ( $\Delta t=10 \mathrm{~ms}$, red; $\Delta t=-30 \mathrm{~ms}$, blue). No significant change in PPRs occurred (paired two-tailed Student's $t$ test). Bottom, Coefficient of variation of EPSPs was calculated before $\left(\mathrm{CV}_{b}\right)$ and after $\left(\mathrm{CV}_{\mathrm{a}}\right)$ the respective STDP protocols ( $\Delta t=10 \mathrm{~ms}$, red; $\Delta t=-30 \mathrm{~ms}$, blue). Significant changes in CVs are indicated $\left(^{*} p<0.05\right.$, paired two-tailed Student's $t$ test). For comparison, inset shows the relation of the squared CV ratios to EPSP ratios, a plot in which the location of data points allows an interpretation of which synaptic parameter $(n, p$, or $q)$ has changed after plasticity (Bekkers and Stevens, 1990; Malinow and Tsien, 1990; Manabe et al., 1993). When the EPSP ratio is bigger than 1 (LTP), points located above the diagonal line indicate an increase in $p$ and/or $n$, and points located on the horizontal dashed line indicate an increase in $q$. The same is true for the case of an EPSP ratio smaller than 1 (LTD), only that points located below the diagonal indicate a decrease in $p$ and/or $n$.

Caille et al., 1996), we neither did attempt to distinguish between direct and indirect pathway SPNs that are thought to express different dopamine receptor subtypes, nor did we attempt to describe dopamine receptor location. The locus of dopamine receptors required for corticostriatal plasticity may be on other striatal neuronal types as has been recently demonstrated using HFS to induce LTD (Wang et al., 2006). However, LTP and LTD was not observed in every single SPN that underwent a normally plasticity-inducing spike-timing protocol (e.g., $\Delta t=+10$ or -30 $\mathrm{ms}$ ), potentially indicating that neurons without dopamine $D_{1} / D_{5}$ receptors failed to potentiate or depress. This is unlikely because failures in plasticity induction are also seen in other brain areas when using similar STDP protocols as used in the present study (Magee and Johnston, 1997; Markram et al., 1997; Froemke et al., 2005; Bender et al., 2006).

\section{NMDARs as coincidence detectors in striatal STDP}

NMDARs are thought to function as coincidence detectors in the induction of cortical STDP by gating supralinear calcium influx into dendritic spines during causal EPSP-AP timing and sublinear calcium influx during anticausal AP-EPSP timing (Koester and Sakmann, 1998; Lisman, 2001; Dan and Poo, 2004). The present study supports this role of NMDARs as coincidence detectors in corticostriatal STDP, because neither consistent LTP

nor LTD was observed in the presence of NMDAR antagonists. Supporting this view, it was demonstrated that the close timing $(\Delta t=10 \mathrm{~ms})$ of a single spike to up-state onset yields maximal supralinear calcium increases in higher-order dendrites (Kerr and Plenz, 2004), an effect that was also dependent on NMDAR activation.

\section{Corticostriatal spike timing activates several plasticity expression mechanisms}

The combined investigation of paired pulse and CV data suggests that spiketiming-dependent LTP is expressed by an increase in the number of release sites or by activation of silent synapses (Isaac et al., 1995; Liao et al., 1995), or by a mix of the two. Activation of silent synapses has been suggested to underlie plasticity in other brain regions and could be brought about in SPNs by dopamine $D_{1} / D_{5}$ receptormediated postsynaptic insertion of AMPARs (Chao et al., 2002; Sun et al., 2005). Conversely, LTD in control conditions was expressed by reduced quantal size that might result from postsynaptic removal of AMPARs or from their reduced responsiveness to glutamate (Malenka and Nicoll, 1999). When dopamine $\mathrm{D}_{2}$ receptors were blocked, LTD originated from decreases in the number of release sites or active synapses. The question arises how two apparently different mechanisms can underlie spike-timing-dependent LTD, depending on the activation of distinct dopamine receptor subtypes. Dopamine $\mathrm{D}_{1} / \mathrm{D}_{5}$ receptor activation might be required not only for postsynaptic insertion of AMPARs but also for their removal. Such postsynaptic removal of AMPARs might result in both reduced quantal size or silent synapses, depending on dopamine $\mathrm{D}_{2}$ receptor activation. Thus, corticostriatal STDP potentially uses different synaptic expression mechanisms than HFS-induced plasticity, in which changes in release probability or terminal excitability were described (Garcia-Munoz et al., 1992; Choi and Lovinger, 1997a; Ronesi and Lovinger, 2005). However, PPR and CV analysis merely represent a first step to understand the synaptic expression mechanisms of striatal STDP without directly measuring them.

\section{Physiological relevance of single spikes in the striatum}

Numerous in vitro studies have reported that plasticity is induced in SPNs by massive high-frequency electrical stimulation (typically $100 \mathrm{~Hz}$ ) of the overlying cortex and that this plasticity depends on dopamine (Calabresi et al., 1992b; Lovinger et al., 1993; Wickens et al., 1996) and dopamine receptor activation (Kerr and Wickens, 2001; Reynolds et al., 2001). A major finding of the present study is that, while maintaining a low presynaptic stimulation frequency $(0.1 \mathrm{~Hz})$, bidirectional plasticity is induced in SPNs by timing a single AP with the cortical stimulation. Such sparse AP activity with single spikes occurring at low frequency is also found in anesthetized and behaving animals in both cortical 
layer 5A principal neurons (Manns et al., 2004; de Kock et al., 2007) and target SPNs (Wilson and Groves, 1981; Hikosaka et al., 1989; Wilson and Kawaguchi, 1996; Wickens and Wilson, 1998; Mahon et al., 2006). We also found that bursts of APs instead of single spikes did not increase striatal STDP strength. In contrast, in hippocampus and neocortex bursts of APs are often required for plasticity, suggesting that a single backpropagating AP does not provide sufficient postsynaptic depolarization for plasticity induction (Magee and Johnston, 1997; Lisman and Spruston, 2005; Nevian and Sakmann, 2006) (but see Feldman, 2000; Froemke et al., 2005).

This study demonstrates that the coincidence of single APs in striatal SPNs with cortical activation is capable of changing the strength of corticostriatal synapses. Although spiking is sparse in striatum and many up states contain no APs (Wilson and Groves, 1981; Wickens and Wilson, 1998), single APs do backpropagate into higher-order dendrites during up states (Kerr and Plenz, 2002). This reliable single AP backpropagation into higher-order dendrites most likely results from active dendritic conductances specifically available to SPNs (Wilson and Kawaguchi, 1996). In many other brain areas, backpropagating APs decline in amplitude with distance from the soma or display branch-point failures (Turner et al., 1991; Spruston et al., 1995; Waters et al., 2003), and bursts of APs might be required to induce AP-timingbased plasticity.

The present study implies that, during cortically driven up states, a single AP may be capable of engaging mechanisms for depressing or enhancing single synapses that are involved in generating that up state. For this to occur, the timing of the backpropagating AP relative to the cortical inputs will dictate the direction of the plasticity but only when the third factor, dopamine, is phasically increased. Importantly, this dependence on dopamine receptor activation distinguishes corticostriatal from intracortical spike-timing-based plasticity. The timing of APs relative to arriving excitatory inputs is not enough to induce corticostriatal plasticity, implying that ongoing activity does not affect synaptic strength unless there is a "reward signal."

\section{References}

Abercrombie ED, Keefe KA, DiFrischia DS, Zigmond MJ (1989) Differential effect of stress on in vivo dopamine release in striatum, nucleus accumbens, and medial frontal cortex. J Neurochem 52:1655-1658.

Akopian G, Walsh JP (2002) Corticostriatal paired-pulse potentiation produced by voltage-dependent activation of NMDA receptors and L-type $\mathrm{Ca}^{2+}$ channels. J Neurophysiol 87:157-165.

Arbuthnott GW, Wickens J (2007) Space, time and dopamine. Trends Neurosci 30:62-69.

Arbuthnott GW, MacLeod NK, Rutherford A (1985) The rat cortico-striatal pathway in vitro. J Physiol (Lond) [Suppl] 367:102.

Arbuthnott GW, Ingham CA, Wickens JR (1998) Modulation by dopamine of rat corticostriatal input. Adv Pharmacol 42:733-736.

Bamford NS, Zhang H, Schmitz Y, Wu NP, Cepeda C, Levine MS, Schmauss C, Zakharenko SS, Zablow L, Sulzer D (2004) Heterosynaptic dopamine neurotransmission selects sets of corticostriatal terminals. Neuron 42:653-663.

Bekkers JM (1994) Quantal analysis of synaptic transmission in the central nervous system. Curr Opin Neurobiol 4:360-365.

Bekkers JM, Stevens CF (1990) Presynaptic mechanism for long-term potentiation in the hippocampus. Nature 346:724-729.

Bender VA, Bender KJ, Brasier DJ, Feldman DE (2006) Two coincidence detectors for spike timing-dependent plasticity in somatosensory cortex. J Neurosci 26:4166-4177.

Bergson C, Mrzljak L, Smiley JF, Pappy M, Levenson R, Goldman-Rakic PS (1995) Regional, cellular, and subcellular variations in the distribution of $\mathrm{D}_{1}$ and $\mathrm{D}_{5}$ dopamine receptors in primate brain. J Neurosci 15:7821-7836.

Bi GQ, Poo MM (1998) Synaptic modifications in cultured hippocampal neurons: dependence on spike timing, synaptic strength, and postsynaptic cell type. J Neurosci 18:10464-10472.

Bolam JP, Bergman H, Graybiel AM, Kimura M, Plenz D, Seung HS, Surmeier DJ, Wickens JR (2006) Group report: microcircuits, molecules, and motivated behavior-microcircuits in the striatum. In: Microcircuits: the interface between neurons and global brain function (Grillner S, ed), pp 165-190. Cambridge, MA: MIT.

Brecht M, Roth A, Sakmann B (2003) Dynamic receptive fields of reconstructed pyramidal cells in layers 3 and 2 of rat somatosensory barrel cortex. J Physiol (Lond) 553:243-265.

Bull DR, Palij P, Sheehan MJ, Millar J, Stamford JA, Kruk ZL, Humphrey PP (1990) Application of fast cyclic voltammetry to measurement of electrically evoked dopamine overflow from brain slices in vitro. J Neurosci Methods 32:37-44.

Caille I, Dumartin B, Bloch B (1996) Ultrastructural localization of D1 dopamine receptor immunoreactivity in rat striatonigral neurons and its relation with dopaminergic innervation. Brain Res 730:17-31.

Calabresi P, Mercuri NB, Stefani A, Bernardi G (1990) Synaptic and intrinsic control of membrane excitability of neostriatal neurons. I. An in vivo analysis. J Neurophysiol 63:651-662.

Calabresi P, Pisani A, Mercuri NB, Bernardi G (1992a) Long-term potentiation in the striatum is unmasked by removing the voltage-dependent magnesium block of NMDA receptor channels. Eur J Neurosci 4:929-935.

Calabresi P, Maj R, Pisani A, Mercuri NB, Bernardi G (1992b) Long-term synaptic depression in the striatum: physiological and pharmacological characterization. J Neurosci 12:4224-4233.

Calabresi P, Pisani A, Mercuri NB, Bernardi G (1994) Post-receptor mechanisms underlying striatal long-term depression. J Neurosci 14:4871-4881.

Calabresi P, Fedele E, Pisani A, Fontana G, Mercuri NB, Bernardi G, Raiteri M (1995) Transmitter release associated with long-term synaptic depression in rat corticostriatal slices. Eur J Neurosci 7:1889-1894.

Carter AG, Sabatini BL (2004) State-dependent calcium signaling in dendritic spines of striatal medium spiny neurons. Neuron 44:483-493.

Celikel T, Szostak VA, Feldman DE (2004) Modulation of spike timing by sensory deprivation during induction of cortical map plasticity. Nat Neurosci 7:534-541.

Chao SZ, Ariano MA, Peterson DA, Wolf ME (2002) D1 dopamine receptor stimulation increases GluR1 surface expression in nucleus accumbens neurons. J Neurochem 83:704-712.

Chergui K, Suaud-Chagny MF, Gonon F (1994) Nonlinear relationship between impulse flow, dopamine release and dopamine elimination in the rat brain in vivo. Neuroscience 62:641-645.

Choi S, Lovinger DM (1997a) Decreased probability of neurotransmitter release underlies striatal long-term depression and postnatal development of corticostriatal synapses. Proc Natl Acad Sci USA 94:2665-2670.

Choi S, Lovinger DM (1997b) Decreased frequency but not amplitude of quantal synaptic responses associated with expression of corticostriatal long-term depression. J Neurosci 17:8613-8620.

Costa RM (2007) Plastic corticostriatal circuits for action learning: what's dopamine got to do with it? Ann NY Acad Sci 1104:172-191.

Cummings JA, Mulkey RM, Nicoll RA, Malenka RC (1996) $\mathrm{Ca}^{2+}$ signaling requirements for long-term depression in the hippocampus. Neuron 16:825-833.

Czubayko U, Plenz D (2002) Fast synaptic transmission between striatal spiny projection neurons. Proc Natl Acad Sci USA 99:15764-15769.

Dan Y, Poo MM (2004) Spike timing-dependent plasticity of neural circuits. Neuron 44:23-30.

David HN, Ansseau M, Abraini JH (2005) Dopamine-glutamate reciprocal modulation of release and motor responses in the rat caudate-putamen and nucleus accumbens of "intact" animals. Brain Res Brain Res Rev 50:336-360.

Day M, Wang Z, Ding J, An X, Ingham CA, Shering AF, Wokosin D, Ilijic E, Sun Z, Sampson AR, Mugnaini E, Deutch AY, Sesack SR, Arbuthnott GW, Surmeier DJ (2006) Selective elimination of glutamatergic synapses on striatopallidal neurons in Parkinson disease models. Nat Neurosci 9:251-259.

de Kock CP, Bruno RM, Spors H, Sakmann B (2007) Layer and cell type specific suprathreshold stimulus representation in primary somatosensory cortex. J Physiol (Lond) 581:139-154. 
Del Castillo J, Katz B (1954) Quantal components of the end-plate potential. J Physiol (Lond) 124:560-573.

Desce JM, Godeheu G, Galli T, Artaud F, Cheramy A, Glowinski J (1992) L-glutamate-evoked release of dopamine from synaptosomes of the rat striatum: involvement of AMPA and $N$-methyl-D-aspartate receptors. Neuroscience 47:333-339.

Dugast C, Suaud-Chagny MF, Gonon F (1994) Continuous in vivo monitoring of evoked dopamine release in the rat nucleus accumbens by amperometry. Neuroscience 62:647-654.

Faber DS, Korn H (1991) Applicability of the coefficient of variation method for analyzing synaptic plasticity. Biophys J 60:1288-1294.

Feldman DE (2000) Timing-based LTP and LTD at vertical inputs to layer II/III pyramidal cells in rat barrel cortex. Neuron 27:45-56.

Fino E, Glowinski J, Venance L (2005) Bidirectional activity-dependent plasticity at corticostriatal synapses. J Neurosci 25:11279-11287.

Froemke RC, Poo MM, Dan Y (2005) Spike-timing-dependent synaptic plasticity depends on dendritic location. Nature 434:221-225.

Garcia-Munoz M, Young SJ, Groves PM (1992) Presynaptic long-term changes in excitability of the corticostriatal pathway. NeuroReport $3: 357-360$.

Gerfen CR (1992) The neostriatal mosaic: multiple levels of compartmental organization in the basal ganglia. Annu Rev Neurosci 15:285-320.

Gerfen CR (2006) Indirect-pathway neurons lose their spines in Parkinson disease. Nat Neurosci 9:157-158.

Gerfen CR, Engber TM, Mahan LC, Susel Z, Chase TN, Monsma Jr FJ, Sibley DR (1990) D1 and D2 dopamine receptor-regulated gene expression of striatonigral and striatopallidal neurons. Science 250:1429-1432.

Gerfen CR, Keefe KA, Gauda EB (1995) $D_{1}$ and $D_{2}$ dopamine receptor function in the striatum: coactivation of $\mathrm{D}_{1}$ - and $\mathrm{D}_{2}$-dopamine receptors on separate populations of neurons results in potentiated immediate early gene response in $\mathrm{D}_{1}$-containing neurons. J Neurosci 15:8167-8176.

Herdon H, Strupish J, Nahorski SR (1987) Endogenous dopamine release from rat striatal slices and its regulation by D-2 autoreceptors: effects of uptake inhibitors and synthesis inhibition. Eur J Pharmacol 138:69-76.

Herrera-Marschitz M, You ZB, Goiny M, Meana JJ, Silveira R, Godukhin OV, Chen Y, Espinoza S, Pettersson E, Loidl CF, Lubec G, Andersson K, Nylander I, Terenius L, Ungerstedt U (1996) On the origin of extracellular glutamate levels monitored in the basal ganglia of the rat by in vivo microdialysis. J Neurochem 66:1726-1735.

Hikosaka O, Sakamoto M, Usui S (1989) Functional properties of monkey caudate neurons. I. Activities related to saccadic eye movements. J Neurophysiol 61:780-798.

Ingham CA, Hood SH, Arbuthnott GW (1989) Spine density on neostriatal neurones changes with 6-hydroxydopamine lesions and with age. Brain Res 503:334-338.

Isaac JT, Nicoll RA, Malenka RC (1995) Evidence for silent synapses: implications for the expression of LTP. Neuron 15:427-434.

Jacob V, Brasier DJ, Erchova I, Feldman D, Shulz DE (2007) Spike timingdependent synaptic depression in the in vivo barrel cortex of the rat. J Neurosci 27:1271-1284.

Jiang ZG, North RA (1991) Membrane properties and synaptic responses of rat striatal neurones in vitro. J Physiol (Lond) 443:533-553.

Kawagoe KT, Garris PA, Wiedemann DJ, Wightman RM (1992) Regulation of transient dopamine concentration gradients in the microenvironment surrounding nerve terminals in the rat striatum. Neuroscience 51:55-64.

Kawaguchi Y (1993) Physiological, morphological, and histochemical characterization of three classes of interneurons in rat neostriatum. J Neurosci 13:4908-4923.

Kawaguchi Y, Wilson CJ, Emson PC (1989) Intracellular recording of identified neostriatal patch and matrix spiny cells in a slice preparation preserving cortical inputs. J Neurophysiol 62:1052-1068.

Kerr JN, Plenz D (2002) Dendritic calcium encodes striatal neuron output during up-states. J Neurosci 22:1499-1512.

Kerr JN, Plenz D (2004) Action potential timing determines dendritic calcium during striatal up-states. J Neurosci 24:877-885.

Kerr JN, Wickens JR (2001) Dopamine D-1/D-5 receptor activation is required for long-term potentiation in the rat neostriatum in vitro. J Neurophysiol 85:117-124.

Kerr JN, Greenberg D, Helmchen F (2005) Imaging input and output of neocortical networks in vivo. Proc Natl Acad Sci USA 102:14063-14068.

Kim J, Alger BE (2001) Random response fluctuations lead to spurious paired-pulse facilitation. J Neurosci 21:9608-9618.
Kita H (1996) Glutamatergic and GABAergic postsynaptic responses of striatal spiny neurons to intrastriatal and cortical stimulation recorded in slice preparations. Neuroscience 70:925-940.

Kita H, Kita T, Kitai ST (1985) Active membrane properties of rat neostriatal neurons in an in vitro slice preparation. Exp Brain Res 60:54-62.

Koester HJ, Sakmann B (1998) Calcium dynamics in single spines during coincident pre- and postsynaptic activity depend on relative timing of back-propagating action potentials and subthreshold excitatory postsynaptic potentials. Proc Natl Acad Sci USA 95:9596-9601.

Koos T, Tepper JM (1999) Inhibitory control of neostriatal projection neurons by GABAergic interneurons. Nat Neurosci 2:467-472.

Koos T, Tepper JM, Wilson CJ (2004) Comparison of IPSCs evoked by spiny and fast-spiking neurons in the neostriatum. J Neurosci 24:7916-7922.

Kotter R, Wickens J (1995) Interactions of glutamate and dopamine in a computational model of the striatum. J Comput Neurosci 2:195-214.

Lee AK, Manns ID, Sakmann B, Brecht M (2006) Whole-cell recordings in freely moving rats. Neuron 51:399-407.

Liao D, Hessler NA, Malinow R (1995) Activation of postsynaptically silent synapses during pairing-induced LTP in CA1 region of hippocampal slice. Nature 375:400-404.

Lisman J, Spruston N (2005) Postsynaptic depolarization requirements for LTP and LTD: a critique of spike timing-dependent plasticity. Nat Neurosci 8:839-841.

Lisman JE (2001) Three $\mathrm{Ca}^{2+}$ levels affect plasticity differently: the LTP zone, the LTD zone and no man's land. J Physiol (Lond) 532:285.

Louilot A, Le Moal M, Simon H (1986) Differential reactivity of dopaminergic neurons in the nucleus accumbens in response to different behavioral situations. An in vivo voltammetric study in free moving rats. Brain Res 397:395-400.

Lovinger DM, Tyler EC, Merritt A (1993) Short- and long-term synaptic depression in rat neostriatum. J Neurophysiol 70:1937-1949.

Magee JC, Johnston D (1997) A synaptically controlled, associative signal for Hebbian plasticity in hippocampal neurons. Science 275:209-213.

Mahon S, Vautrelle N, Pezard L, Slaght SJ, Deniau JM, Chouvet G, Charpier S (2006) Distinct patterns of striatal medium spiny neuron activity during the natural sleep-wake cycle. J Neurosci 26:12587-12595.

Malenka RC, Nicoll RA (1999) Long-term potentiation-a decade of progress? Science 285:1870-1874.

Malinow R, Tsien RW (1990) Presynaptic enhancement shown by wholecell recordings of long-term potentiation in hippocampal slices. Nature 346:177-180.

Manabe T, Wyllie DJ, Perkel DJ, Nicoll RA (1993) Modulation of synaptic transmission and long-term potentiation: effects on paired pulse facilitation and EPSC variance in the CA1 region of the hippocampus. J Neurophysiol 70:1451-1459.

Manns ID, Sakmann B, Brecht M (2004) Sub- and suprathreshold receptive field properties of pyramidal neurones in layers $5 \mathrm{~A}$ and $5 \mathrm{~B}$ of rat somatosensory barrel cortex. J Physiol (Lond) 556:601-622.

Margrie TW, Brecht M, Sakmann B (2002) In vivo, low-resistance, wholecell recordings from neurons in the anaesthetized and awake mammalian brain. Pflügers Arch 444:491-498.

Markram H, Lubke J, Frotscher M, Sakmann B (1997) Regulation of synaptic efficacy by coincidence of postsynaptic APs and EPSPs. Science 275:213-215.

Meredith RM, Floyer-Lea AM, Paulsen O (2003) Maturation of long-term potentiation induction rules in rodent hippocampus: role of GABAergic inhibition. J Neurosci 23:11142-11146.

Montague PR, Dayan P, Sejnowski TJ (1996) A framework for mesencephalic dopamine systems based on predictive Hebbian learning. J Neurosci 16:1936-1947.

Montague PR, Hyman SE, Cohen JD (2004) Computational roles for dopamine in behavioural control. Nature 431:760-767.

Nevian T, Sakmann B (2004) Single spine $\mathrm{Ca}^{2+}$ signals evoked by coincident EPSPs and backpropagating action potentials in spiny stellate cells of layer 4 in the juvenile rat somatosensory barrel cortex. J Neurosci 24:1689-1699.

Nevian T, Sakmann B (2006) Spine $\mathrm{Ca}^{2+}$ signaling in spike-timingdependent plasticity. J Neurosci 26:11001-11013.

Nisenbaum ES, Wilson CJ (1995) Potassium currents responsible for inward and outward rectification in rat neostriatal spiny projection neurons. J Neurosci 15:4449-4463. 
Nishiyama M, Hong K, Mikoshiba K, Poo MM, Kato K (2000) Calcium stores regulate the polarity and input specificity of synaptic modification. Nature 408:584-588.

Onn SP, West AR, Grace AA (2000) Dopamine-mediated regulation of striatal neuronal and network interactions. Trends Neurosci 23:S48-S56.

Partridge JG, Apparsundaram S, Gerhardt GA, Ronesi J, Lovinger DM (2002) Nicotinic acetylcholine receptors interact with dopamine in induction of striatal long-term depression. J Neurosci 22:2541-2549.

Plenz D (2003) When inhibition goes incognito: feedback interaction between spiny projection neurons in striatal function. Trends Neurosci 26:436-443.

Plenz D, Kitai ST (1998) Up and down states in striatal medium spiny neurons simultaneously recorded with spontaneous activity in fast-spiking interneurons studied in cortex-striatum-substantia nigra organotypic cultures. J Neurosci 18:266-283.

Reynolds JN, Wickens JR (2000) Substantia nigra dopamine regulates synaptic plasticity and membrane potential fluctuations in the rat neostriatum, in vivo. Neuroscience 99:199-203.

Reynolds JN, Hyland BI, Wickens JR (2001) A cellular mechanism of reward-related learning. Nature 413:67-70.

Richfield EK, Penney JB, Young AB (1989) Anatomical and affinity state comparisons between dopamine D1 and D2 receptors in the rat central nervous system. Neuroscience 30:767-777.

Ronesi J, Lovinger DM (2005) Induction of striatal long-term synaptic depression by moderate frequency activation of cortical afferents in rat. J Physiol (Lond) 562:245-256.

Sanes JR, Lichtman JW (1999) Can molecules explain long-term potentiation? Nat Neurosci 2:597-604

Schultz W (2002) Getting formal with dopamine and reward. Neuron $36: 241-263$

Sesack SR, Aoki C, Pickel VM (1994) Ultrastructural localization of $\mathrm{D}_{2}$ receptor-like immunoreactivity in midbrain dopamine neurons and their striatal targets. J Neurosci 14:88-106.

Sjostrom PJ, Turrigiano GG, Nelson SB (2001) Rate, timing, and cooperativity jointly determine cortical synaptic plasticity. Neuron 32:1149-1164.

Sola E, Prestori F, Rossi P, Taglietti V, D’Angelo E (2004) Increased neurotransmitter release during long-term potentiation at mossy fibre-granule cell synapses in rat cerebellum. J Physiol (Lond) 557:843-861.

Spruston N, Schiller Y, Stuart G, Sakmann B (1995) Activity-dependent action potential invasion and calcium influx into hippocampal CA1 dendrites. Science 268:297-300.

Sun X, Zhao Y, Wolf ME (2005) Dopamine receptor stimulation modulates AMPA receptor synaptic insertion in prefrontal cortex neurons. J Neurosci 25:7342-7351.

Tepper JM, Koos T, Wilson CJ (2004) GABAergic microcircuits in the neostriatum. Trends Neurosci 27:662-669.

Tunstall MJ, Oorschot DE, Kean A, Wickens JR (2002) Inhibitory interactions between spiny projection neurons in the rat striatum. J Neurophysiol 88:1263-1269.

Turner RW, Meyers DE, Richardson TL, Barker JL (1991) The site for initi- ation of action potential discharge over the somatodendritic axis of rat hippocampal CA1 pyramidal neurons. J Neurosci 11:2270-2280.

Tzounopoulos T, Kim Y, Oertel D, Trussell LO (2004) Cell-specific, spike timing-dependent plasticities in the dorsal cochlear nucleus. Nat Neurosci 7:719-725.

Walsh JP (1993) Depression of excitatory synaptic input in rat striatal neurons. Brain Res 608:123-128.

Walsh JP, Dunia R (1993) Synaptic activation of N-methyl-D-aspartate receptors induces short-term potentiation at excitatory synapses in the striatum of the rat. Neuroscience 57:241-248.

Wang Z, Kai L, Day M, Ronesi J, Yin HH, Ding J, Tkatch T, Lovinger DM, Surmeier DJ (2006) Dopaminergic control of corticostriatal long-term synaptic depression in medium spiny neurons is mediated by cholinergic interneurons. Neuron 50:443-452.

Waters J, Larkum M, Sakmann B, Helmchen F (2003) Supralinear $\mathrm{Ca}^{2+}$ influx into dendritic tufts of layer $2 / 3$ neocortical pyramidal neurons in vitro and in vivo. J Neurosci 23:8558-8567.

Wickens J (1990) Striatal dopamine in motor activation and rewardmediated learning: steps towards a unifying model. J Neural Transm 80:9-31.

Wickens JR, Arbuthnott GW (1993) The corticostriatal system on computer simulation: an intermediate mechanism for sequencing of actions. Prog Brain Res 99:325-339.

Wickens JR, Wilson CJ (1998) Regulation of action-potential firing in spiny neurons of the rat neostriatum in vivo. J Neurophysiol 79:2358-2364.

Wickens JR, Alexander ME, Miller R (1991) Two dynamic modes of striatal function under dopaminergic-cholinergic control: simulation and analysis of a model. Synapse 8:1-12.

Wickens JR, Begg AJ, Arbuthnott GW (1996) Dopamine reverses the depression of rat corticostriatal synapses which normally follows highfrequency stimulation of cortex in vitro. Neuroscience 70:1-5.

Wilson C (1990) The basal ganglia. In: The synaptic organization of the brain (Sheperd GM, ed), 279-316. New York: Oxford UP.

Wilson CJ, Groves PM (1981) Spontaneous firing patterns of identified spiny neurons in the rat neostriatum. Brain Res 220:67-80.

Wilson CJ, Kawaguchi Y (1996) The origins of two-state spontaneous membrane potential fluctuations of neostriatal spiny neurons. J Neurosci 16:2397-2410.

Wittenberg GM, Wang SS (2006) Malleability of spike-timing-dependent plasticity at the CA3-CA1 synapse. J Neurosci 26:6610-6617.

Young AM, Joseph MH, Gray JA (1992) Increased dopamine release in vivo in nucleus accumbens and caudate nucleus of the rat during drinking: a microdialysis study. Neuroscience 48:871-876.

Zhou FM, Liang Y, Dani JA (2001) Endogenous nicotinic cholinergic activity regulates dopamine release in the striatum. Nat Neurosci 4:1224-1229.

Zhou FM, Wilson CJ, Dani JA (2002) Cholinergic interneuron characteristics and nicotinic properties in the striatum. J Neurobiol 53:590-605.

Zucker RS (1989) Short-term synaptic plasticity. Annu Rev Neurosci 12:1331. 